\title{
O RETO-ROMÂNICO: UNIDADE E FRAGMENTAÇÃO
}

\author{
Mário Eduardo Viaro* \\ Resumo: Os manuais de linguística ou filologia \\ românica costumam incluir o reto-românico como uma \\ das principais línguas neolatinas, ao lado do português, \\ espanhol, francês, italiano e romeno. No entanto, tal \\ denominação refere-se na verdade a um conjunto \\ extremamente heterogêneo de línguas, com uma \\ profunda fragmentação dialetal. Acresce-se a isso o \\ recente problema da padronização da norma escrita. \\ Este artigo $^{1}$ pretende especificamente apresentar a \\ situação linguística atual dos Grisões e o problema da \\ convivência do romanche com os dialetos alemães e o \\ italianos.
}

Palavras-chave: Reto-românico; dialetologia; contato linguístico.

\footnotetext{
* Universidade de São Paulo.

${ }^{1}$ Extraído da tese de doutorado em Filologia Românica $A$ construção verbo + advérbio de lugar no romanche: herança latina ou decalque germânico? defendida em 2001. As bibliotecas consultadas sobre os temas tratados neste trabalho foram Bibliothèque Publique et Universitaire de Genève, Bibliothek der Universität Bern, Bibliothèque de la Université de Fribourg, Bibliothek des Romanischen Seminars der Universität Zürich, Züricher Kantonsbibliothek, Graubündner Kantonsbibliothek, Chesa Planta (em Samedan), Klosterbibliothek (em Mustér) e o Institut Dicziunari Rumantsch Grischun (em Chur).
} 


\section{Introdução}

O pesquisador que se põe a estudar o reto-românico, logo se depara com um obstáculo, que parece intransponível à primeira vista: a sua fragmentação dialetal. Descobre, com o manuseio de alguns textos, que, na verdade, se trata de um conjunto de variantes linguísticas. Dizendo de outro modo, não existe uma língua românica uniforme, mas três grupos de falares reto-românicos, separados geográfica e politicamente, bastante distintos, a ponto de ser possível afirmar que a distância entre essas variantes pode ser tão grande quanto a que há entre o francês e o português. Cada um desses grupos apresenta, ainda, uma nova fragmentação interna. Mesmo que o pesquisador resolva dedicar-se apenas a um dos grupos, continuará perplexo diante da grande distância fonética, morfossintática e semântica que há, por exemplo, entre o romanche suíço da região de Mustér e o de Santa Maria in Val Müstair. Depreender uma "unidade reto-românica", portanto, não é coisa imediata e por vezes pensamos que ela nasce mais pela exclusão de traços dos dialetos galo-românicos e italo-românicos do que propriamente por características comuns. A fragmentação dialetal chega a um nível tal, que cada aldeia tem sua forma peculiar de falar, embora estejam fixadas há séculos algumas normas escritas. Exclusivamente com o propósito de facilitar a compreensão do assunto, nomeiam-se as aldeias com o nome autóctone. Nem sempre é fácil saber que Ilanz, citada nos textos em alemão e Glion, nos textos em reto-românico, são apenas nomes diferentes para o mesmo lugar.

Os manuais de filologia ou linguística românica falam do "rético" como uma língua provinda do latim, ao lado do português, castelhano, catalão, occitano, francês, italiano, dalmático e romeno. Situada entre as "línguas românicas ocidentais", teria ora características do galo-românico, ora do italo-românico, além de suas próprias características. Assim, mantêm-se, como no francês e occitano, os grupos fonéticos $c l$-, $p l$-, $b l$-, mas outros fenômenos, como a palatalização do $c$ diante de $a$ (e consequente transformação $a>e$ ), 
a vocalização de $-l>-u$, a palatalização do $u>\ddot{u}$, o plural em $-i$ ou em $-s$, têm maior ou menor divulgação dentro da área dos inúmeros falares.

Normalmente esses fatores de divergência fonética apontam para a fragmentação da "língua rética", que é tradicionalmente dividida em três grupos, cujas diferenças são, não raro, vistas de forma superficial e imprecisa nos manuais. O primeiro problema que se colocou foi se essa "língua" realmente existe ou se é mais um conjunto de dialetos italianos.

Foi Ascoli ${ }^{2}$ o primeiro a apontar as diferenças desse grupo em relação ao italiano. O italiano e o alemão teriam sido os responsáveis pelo esfacelamento do continuum, promovendo, assim, o isolamento dos três grupos. Ascoli usou, para essa unidade, o termo genérico ladino e foi o primeiro a nomear os três grupos de maneira geográfica, a saber, ladino occidentale, centrale e orientale. Foi Gartner ${ }^{3}$ que usou, em textos científicos, o termo genérico Rätoromanisch para a mesma pretensa unidade. Atualmente esse termo alemão se refere exclusivamente ao conjunto de variantes ocidentais, sinônimo de Bündnerromanisch (ou simplesmente Romanisch), em oposição ao Ladinisch (central) e ao Friaulisch (oriental). Discutir-se-ia acaloradamente, a seguir, se o reto-românico faz ou não parte dos dialetos italianos, surgindo, assim, a conhecida questione ladina. Contra a ideia da unidade reto-românica citem-se Salvioni ${ }^{4}$ e Battisti, ${ }^{5}$ que os ligavam aos dialetos lombardo e vêneto do italiano.

Por outro lado, os que partem do pressuposto da unidade dos três grupos dificilmente se põem a descrever como seria aquele estágio hipotético primitivo. Conhece-se, no entanto, uma reconstrução do proto-reto-românico por Leonard. ${ }^{6}$ Para os que

\footnotetext{
${ }^{2}$ ASCOLI. Saggi ladini.

${ }^{3}$ GARTNER. Rätoromanische Grammatik.

${ }^{4}$ SALVIONI. Ladinia e Italia.

${ }^{5}$ BATTISTI. Sulla pretesa unità ladina.

${ }^{6}$ LEONARD. Proto-Raeto-Romance and French; LEONARD. The vocalism of Proto-Raeto-Romance.
} 
partem da idéia de que essa unidade nunca existiu, questiona-se sobretudo se o grupo oriental faria parte do mesmo grupo que envolveria os outros dois.

Pelo aqui dito, percebe-se que outro problema que surge é a denominação da tal unidade e de suas partes. Os manuais usam muito frequentemente, em vez de reto-românico, o termo rético, evidentemente ambíguo, pois representa também a língua pré-romana e não indo-europeia extinta, cujos falantes teriam ocupado parte da área correspondente (mas não os extremos a leste e a oeste) de onde a unidade reto-românica teria surgido. Essa mesma ambiguidade ocorre com os termos vêneto e lígure. Com frequência, a imprecisão terminológica se torna indesejável em estudos diacrônicos. Neste trabalho, os povos pré-romanos são denominadospaleovênetos e lígures, enquanto os dialetos italianos se chamam vêneto e ligúrio. Também se fará uma distinção entre os longobardos, povo germânico que povoou o norte da Itália, e lombardo, dialeto italiano falado ainda atualmente. Para evitar qualquer ambiguidade, também não se utilizará aqui o termo rético para as línguas e dialetos neolatinos em questão. Prefere-se, pelo já dito, o termo reto-românico.

Outro termo que aparece na literatura é romanche, utilizado neste trabalho para os falares ocidentais. Esse termo é autóctone e reuniria as cinco variantes suíças, a saber, o sobresselvano (srs), o subselvano (sts), o sobremirano (srm), o valáder (val) e puter (put). Esses dois últimos, devido à sua proximidade, são comumente reunidos sob a denominação de engadino (eng). Ambíguo também é o termo ladino. Sem se levar em consideração que essa também é a denominação do judeuespanhol (do grupo ibero-românico), encontra-se ainda o termo ladino como sinônimo de engadino. Como se viu acima, Ascoli ${ }^{7}$ chama de ladino toda a unidade reto-românica. E ladino, para piorar, é ainda a única denominação autóctone dos falares

7 ASCOLI. Saggi ladini. 
correspondentes ao ladino centrale de Ascoli. Por isso, neste trabalho utilizar-se-á o termo ladino (lad.) apenas para o grupo central e, para evitar possíveis ambiguidades, anexar-se-á o adjetivo dolomítico, referente à região da Itália onde atualmente se falam essas variantes. O grupo oriental, também na Itália, é tradicionalmente conhecido como friulano (fri.), também fragmentado em dialetos.

Hoje em dia parece não haver dúvidas de que o grupo reto-românico seja um grupo distinto do galo-românico e do italoromânico, mas há quem questione se o romanche, o ladino dolomítico e o friulano formem ou formaram, um dia, realmente uma unidade. ${ }^{8}$ Tentativas de conciliação surgem, por exemplo, com Bec, ${ }^{9}$ que subdivide o galo-românico em galo-românico francês (picardo, valão, loreno, alto normando, angevino, gallot, baixo normando, bourguignon, franciano, pictevino, francoprovençal), galo-românico occitano (limusino, auvergnat, provençal alpino, languedociano, provençal, gascão, catalão oriental e ocidental) e galo-românico cisalpino, que se subdividiria em reto-friulano (romanche, ladino dolomítico, friulano) e galoitaliano (piemontês, lombardo, emiliano-romanhol, ligúrio, vêneto, istriota).

\footnotetext{
${ }^{8}$ KREFELD. Der surselvische Wortschatz, die questione ladina und die quantitative Arealtypologie. Pellegrini, por exemplo, supõe que os falares ladinos fazem parte de dois grupos de substratos: atesinos e cadorinos, esses mais próximos dos friulanos e com influência belunesa e vêneta, aquela com influência do alemão. Cala-se quanto ao romanche e quanto ao friulano, afirma: "io continuo a dubitare che esista in Italia un sistema linguistico unitario delle parlate popolari, ora in progressivo cesimento e annacquamento; dialetti italiani significa per lo più dialetti d'Italia poiché l'italianità è una realtà extralinguistica, specie in um primo tempo, e va ricercata in altri motivi che non si identificano nell'uso popolare di alcuni linguaggi, spesso lontanissimi dalla lingua nazionale di fondamento toscano" (PELLEGRINI. Saggi sul ladino dolomitico e sul friulano, p. 331).
}

${ }^{9}$ BEC. Manuel pratique de philologie. 
Além das variantes supramencionadas, ainda há as normas escritas unificadoras, construtos artificiais, porém muito bem elaboradas, recentemente propostas por Heinrich Schmid. A mais utilizada é o romanche grisão (RG). Trata-se de uma variante escrita elaborada em 1982 para o romanche suíço. Uma segunda norma, concluída em 1998, também proposta por Schmid, é o ladin dolomitan (LD), ainda muito recente e sem a repercussão da primeira. $O$ termo não pôde ser aportuguesado neste trabalho para não se confundir com o termo genérico ladino dolomítico. Representa uma tentativa de unificação escrita de todos os falares dolomíticos. O friulano, diferentemente do romanche e do ladino dolomítico, possui tradição escrita constante e antiga, já dispondo, portanto, de uma koiné, sobre a qual se forma uma norma escrita mais ou menos uniformizada, embora ainda hoje se coloquem discussões sobre a ortografia. Observe-se que tanto o romanche grisão quanto o ladin dolomitan são propostas suprarregionais de norma culta, com finalidades práticas de padronização. Não devem ser confundidas respectivamente com o romanche ou com o ladino dolomítico, nomes genéricos para os dialetos locais, que por si só formariam unidades só atingíveis por meio da reconstrução histórico-comparativa. Fazendo esse estudo microscópico, é surpreendente como não é possível deter-se apenas no fato, como descrição de um detalhe linguístico irrelevante, pelo contrário, tornase urgente uma nova discussão teórica sobre as peculiaridades regionais de línguas românicas em contraposição a toda a România, à luz da intensidade da influência do latim medieval. Os vários elementos envolvidos tanto na herança quanto no contato linguístico em si motivam novos pressupostos a respeito dos substratos e superstratos. 


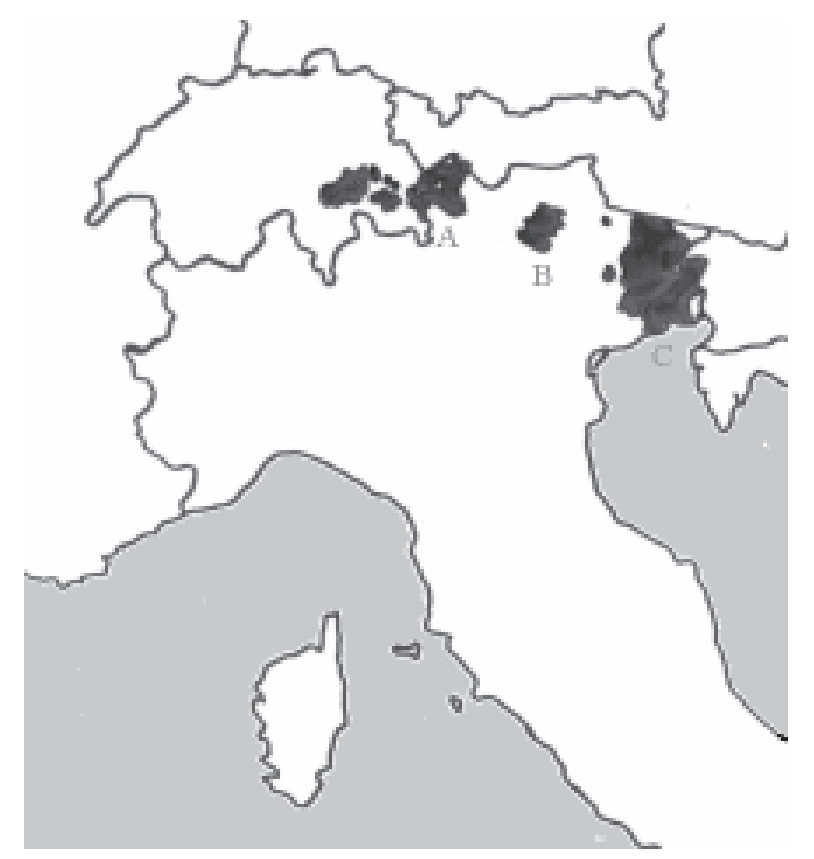

MAPA 1: Os grupos de falares reto-românicos: (A) Romanche; (B) Ladino dolomítico; (C) Friulano.

\section{Os grupos da Suíça}

Os Grisões formam o maior cantão da Suíça. Situado na porção oriental daquele país, entre a Áustria (no mapa 2, AU) e Itália (IT), está rodeado, a oeste, pelos cantões de Sankt Gallen (SG), Glarus (GL), Uri (UR) e Ticino (TI). Nos Grisões não se fala apenas romanche, mas há locais onde se falam exclusivamente $o$ alemão (oficial e dialetos alemânicos) e o italiano (oficial e dialetos lombardos). Pode-se dizer que já não existem falantes monolíngues de reto-românico, seja na Suíça, seja na Itália.

Nos Grisões, atualmente, fala-se apenas italiano em três regiões:

a) Em Poschiavo e em Brusio ( ${ }^{\circ} 1$, do Mapa 2), regiões situadas entre a área do puter e a Itália. 
b) No Vale de Bregaglia (2), abaixo das áreas do subselvano, sobremirano e puter: inclui Vicosoprano, Stampa, Bondo, Soglio.

c) Em San Bernardino, em Mesolcina (Mesocco, Soazza, Lostallo, Verdabbio, Cama, Leggia, Grono, Vittore, Roveredo) e em Calanca (Valbella, Rossa, Augio, Cauco, Landarenca, Selma, Arvigo, Braggio, Buseno, Sta. Maria i. C.), regiões situadas abaixo de Hinterrhein, entre o cantão de Ticino e Itália (3).

No mesmo cantão, fala-se somente alemão em:

a) Samnaun e Laret (4): logo acima da área do valáder. Nessa região fala-se um dialeto bávaro, próximo dos falares tiroleses da Áustria. ${ }^{10}$

b) Obersaxen (5): no meio da área do sobresselvano.

c) Rheinwald (6): área acima da região de fala italiana da Mesolcina e Calanca, incluindo Hinterrhein, Nufenen, Medels i. Rh., Splügen, Sufers. Mais acima, ao sudeste e a leste da área sobresselvana, no Valsertal (7): Vals, St. Martin, mais a leste, no Safiental (8): Safien, Thalkirch, Valendas, Versam, Tenna. Separando as duas regiões do subselvano, na região de Mantogna (9): Tschappina, Urmeins, Thusis, Sils i.D. e Mutten.

d) Avers (10) ao noroeste de Bregaglia.

e) Prättigau (11), bem ao norte do cantão, entre St. Gallen e a Áustria: Fläsch, Maienfeld, Jenins, Malans, Seewis i. Pr., Grüsch, Schiers, Schuders, Landquart, Pany, Fideris, Küblis, Castels, Mastrils, Igis, Valzeina, Luzein, St. Antönien, Rüti i. Pr., Saas i. Pr., Klosters, Monbiel, Zizers, Says, Trimmis, Furna, Jenaz, Fideris, Conters i. Pr. Também na área conhecida como Schanfigg (12), incluindo Chur, Maladers, Calfreisen, Castiel, Lüen, St. Peter, Peist, Langwies, Malix, Passugg, Tschiertschen, Molinis. A oeste desta área e a leste da área sobresselvana, na área de Calanda

\footnotetext{
${ }^{10}$ RITTER. Historische Lautlebre der ausgestorbenen romanischen Mundart von Samnaun.
} 
(13): Untervaz, Haldensteim, Tamins, Felsberg. Acima da área do sobremirano em Churwalden, Frauenkirch, Glaris, Clavadel, Monstein, Sertig Dörfli, Arosa, Davos, Wiesen, Schmitten (14).

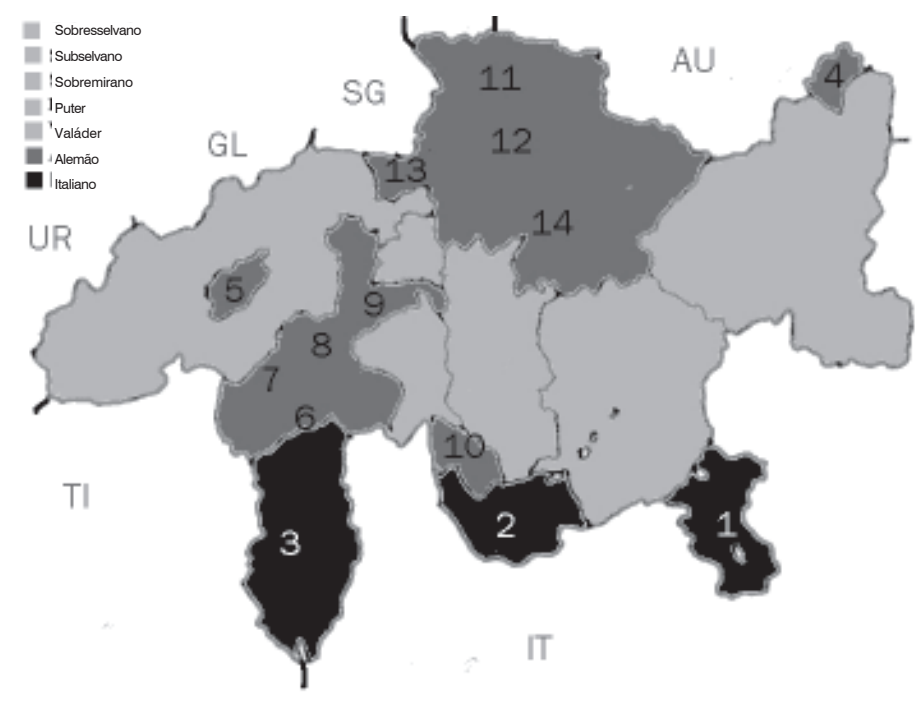

MAPA 2: Línguas dos Grisões

As áreas de fala romanche do mapa são na verdade áreas tradicionais, que tinham maioria romanche em 1860. Nem todos os falantes de romanche vivem atualmente nos Grisões. Em 1980, sabia-se que $29,5 \%$ dos falantes de romanche se encontravam em outros cantões, principalmente em Zurique, Berna, Sankt Gallen, Lucerna e Genebra, sem falar dos que foram para o estrangeiro. Dos que vivem nos Grisões, 59,1\% vivem nas áreas tradicionais. Nessas áreas, há hoje uma grande variação quanto à porcentagem de uso dependendo da região: hoje em dia, a maioria dos habitantes da área do subselvano e do puter falam alemão. Em 1880 cerca de $1,4 \%$ da população suíça utilizava alguma variante romanche como língua materna. Cem anos depois, esse número tinha caído para $0,8 \%$. Em 1990, apenas $0,6 \%$ informava que a língua que dominava melhor era uma variante reto-românica (observe que 
1,4\% respondeu que era o português!). Somando esse dado com a língua que era utilizada no domínio da família, escola e/ou trabalho, o número de falantes subia para $1,0 \%$ da população. ${ }^{11}$ Dentro do cantão dos Grisões, em 1880 o romanche era a língua materna de $39,8 \%$ da população; em 1980 , de $21,9 \%$ e em 1990 , era a língua mais bem dominada de $17 \%$ a $23,6 \% .^{12}$

A região de Bregaglia é importantíssima para nosso estudo, uma vez que o bregalboto, dialeto romanche ali falado extinguiuse no século XIX não em favor do alemão, mas sim do italiano, deixando, além disso, muita documentação. ${ }^{13}$

\subsection{Sobresselvano}

O sobresselvano (que também aparece sob as denominações romontsch ou sursilvan; em alemão oberländisch ou obwaldisch) é falado por 18.000 pessoas na região conhecida como Surselva (em alemão, Bündner Oberland), que vai do Oberalppaß (na fronteira com o cantão de Uri) até Reichenau (no encontro do Reno Anterior com o Reno Posterior) com exceção de Obersaxen. Essa área faz fronteira com os cantões de Sankt Gallen, Glarus, Uri e Ticino. Fala-se sobresselvano nas seguintes regiões: ${ }^{14}$

a) Tujetsch (no 1 do Mapa 3), área mais a oeste da região sobresselvana, que engloba, seguindo o Reno, de leste a oeste: Tschamut, Selva, Ruèras, Camischolas e Sedrun. A subvariante dessa região é bastante peculiar.

b) Val Medel (3), entre a área do Tujetsch e a de Cadi, com Platta a sul e Curaglia a norte.

\footnotetext{
${ }^{11}$ GROSS et al. Rätoromanisch: facts and figures, p. 20.

${ }^{12}$ GROSS et al. Rätoromanisch: facts and figures, p. 22.

${ }^{13}$ DECURTINS. Rätoromanische Chrestomatie, v. 9.

${ }^{14}$ Existe uma interessante enumeração das aldeias sobresselvanas do século. XVIII: DECURTINS. Rätoromanische Chrestomatie, v.4, p. 43-44.
} 
c) Cadi: área do Reno Anterior que agrupa, de leste para oeste: Mustér (2), Compadials, Sumvitg e Surrein (4), Rabius, Trun, Zignau, Lumneins e Schlans (5).

d) Foppa: área a oeste de Cadi e a norte de Obersaxen e Lumnezia, que inclui, de leste a oeste: Breil, Dardin, Danis e Tavanasa (6), Vuorz (7), Andiast (8), Pigniu (9), Siat, Rueun e Schnaus (10). Na área mais oriental do Foppa encontram-se: Ruschein (11), Ladir e Schluein (14), Sagogn (17), Falera (12), Lags (13) e Flem (31). Entre o Foppa e o Lumnezia, na região ao sul do Reno estão: Flond e Luven (15) e Glion (16), Sevgein (19) e Castrisch (20)

e) Lumnezia: área que agrupa, à esquerda do rio Glogn, afluente do Reno: do ponto mais ao sul até o mais ao norte: Vrin e Surin (21), Lumbrein (22), Vignogn (23), Degen (24), Vella (25), Cumbel, Peiden, Murissen (26). Entre o Foppa e Obersaxen está Surcuolm (18). À direita do rio Glogn estão, de sul a norte: Surcasti, S. Martin, Tersnaus, Uors e Camuns (27), Duin (28), Pitatsch (29), Riein (30).

f) Plaun: a área mais oriental, que faz fronteira com a área do subselvano. Ali se falam as duas variantes Trin (32), Bonaduz (33), Razen (34) e Domat (35). Também em Flem (31) falamse o sobresselvano e o subselvano.

O sobresselvano é a mais falada e a mais bem estudada de todas as variantes. Citem-se como obras básicas a extensa gramática de Spescha (1989) e os dicionários de Vieli e Decurtins: ${ }^{15}$ sobresselvanoalemão; alemão-sobresselvano). Também o manual de Liver ${ }^{16}$ estuda essa variante minuciosamente ao lado do valáder. Em 1990, na região descrita acima, $77 \%$ das pessoas consideram o sobresselvano a língua que domina melhor (em Glion, apenas 37\%, em Vrin 96\%).

15 VIELI; DECURTINS. Vocabulari romontsch sursilvan-tudestg; VIELI; DECURTINS. Vocabulari romontsch tudestg-sursilvan.

${ }^{16}$ LIVER. Manuel pratique de romanche sursilvan-vallader. 
Esse valor sobe para $86 \%$ quando se pergunta qual é a língua utilizada em casa, na escola e/ou trabalho (Glion=55\%) e é ainda mais alto quando se pergunta se é compreensível (92\% em toda a área, $87 \%$ em Glion). ${ }^{17}$ Apesar de ser a mais usada das variantes, $o$ sobresselvano não é a que dispõe de textos mais antigos.

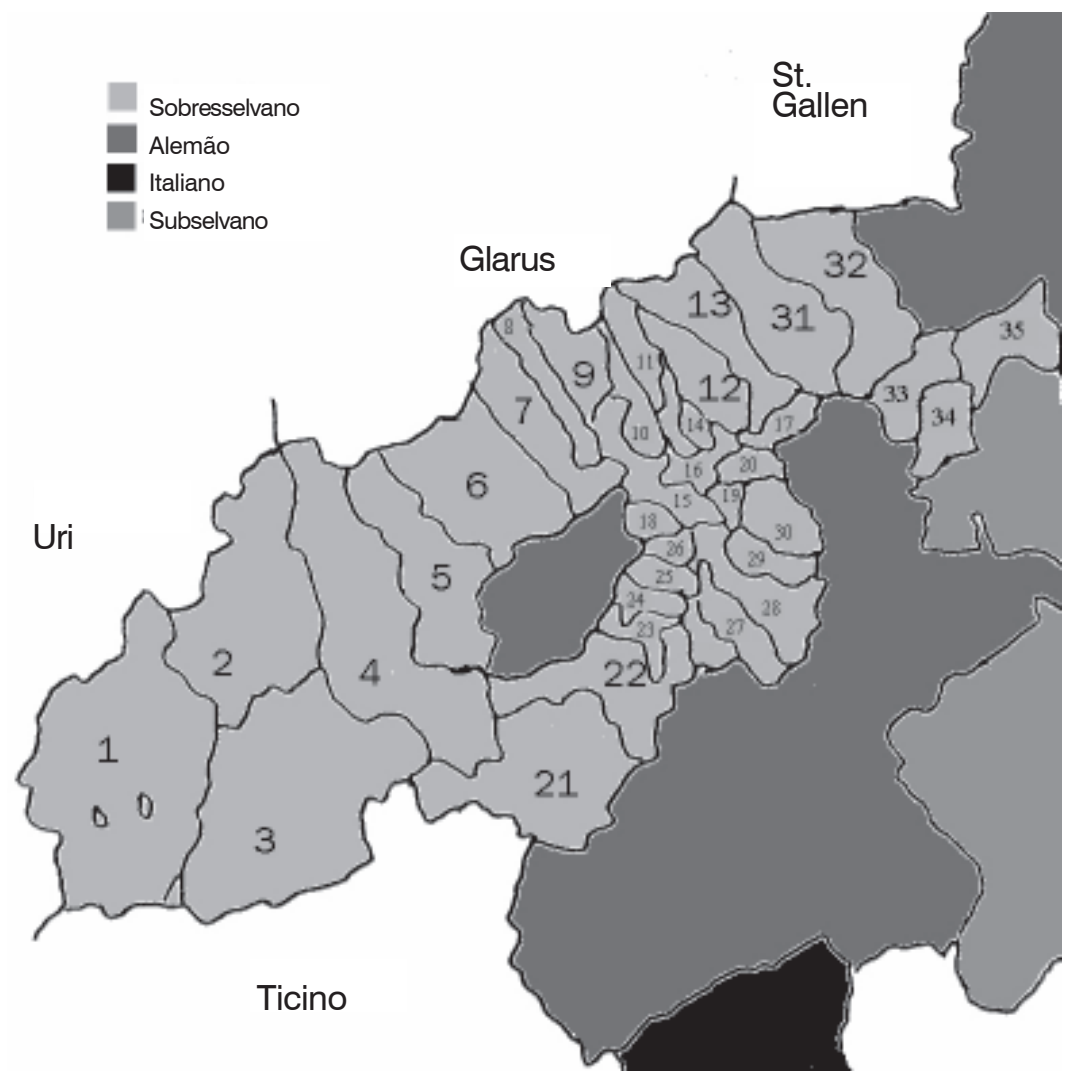

MAPA 3: Área do sobresselvano

Os primeiros textos remontam ao século XVII: Steffan Gabriel, Luci Gabriel (protestantes), Gion Antoni Calvenzano,

${ }^{17}$ GROSS et al. Rätoromanisch: facts and figures, p. 23-26. 
Zacharias da Salo, Balzar Alig (católicos). Os primeiros textos em sobresselvano de que se tem notícia é Ilg vêr sulaz da pievel giuvan "O verdadeiro prazer da juventude", de Steffan Gabriel (1611) e Curt Muossament "Cartilha pequena", de Gion Antoni Calvenzano (1611). O sobresselvano tem tradicionalmente duas ortografias, ${ }^{18}$ uma católica e outra protestante. As diferenças entre essas ortografias é bastante antiga e reflete diferenças fonéticas e lexicais. Assim, a fala de Mustér serviu como modelo para a subvariante católica e a de Glion para a subvariante protestante. Em 1927 houve tentativa de padronização das duas formas, promovida por $G$. Cahannes, a qual só se levou a cabo em 1938 com o dicionário de Vieli. Mesmo assim há ainda sobrevivência de algumas formas, como dir "dizer" que é grafada comogir pelos protestantes. Da mesma forma, $d i$ "dia" se grafa gi, refletindo assim a pronúncia de Lumnezia e Foppa. Gross et al. : ${ }^{19}$

Ilustra-se este falar com um exemplo encontrado em

L'uolp era puspei inaga fomentada. Cheu ha ella viu sin in pégn in tgaper che teneva in toc caschiel en siu bec. "Quei gustass a mi", ha ella tertgau, ed ha clamau al tgaper: "Tgei bi che ti eis! Sche tiu cant ei aschi bials sco tia cumparsa, lu eis ti il pli bi utschi da tuts.".

Tradução: A raposa estava novamente com fome. E eis que ela viu num pinheiro um corvo que tinha um pedaço de queijo em seu bico. "Isso me saberia bem", pensou, e clamou ao corvo: "Que belo que tu és! Se teu canto fosse tão belo quanto tua aparência, serias o mais belo pássaro de todos.”.

Para um morador do Tujetsch ou do Foppa aprender o sobresselvano escrito é quase tão difícil quanto aprender a escrever

\footnotetext{
${ }^{18}$ CAVIEZEL. Geschichte von Verschriftung, Normierung udn Standardisierung des Surselvischen.

${ }^{19}$ GROSS et al. Rätoromanisch: facts and figures, p. 23.
} 
numa outra variante romanche. A artificialidade das cinco normas cultas do romanche, no entanto, ficará mais evidente nos próximos falares que serão descritos.

\subsection{Subselvano}

O subselvano (que os próprios falantes chamam de rumàntsch, sutsilvan; em alemão nidwaldisch ou unterländisch) é falado por 5.000 pessoas na região denominada Subselva (al. Mittelbünden) e também na porção oriental da área sobresselvana, limitando-se ao sul com a Lombardia e separado do sobresselvano pela floresta de Flem. Falam-no as populações de no Reno posterior:

a) Foppa: em Flem (31), juntamente com o sobresselvano.

b) Plaun: região que vai de Tumleastga a Chur: Trin (32), Bonaduz (33), Razen (34) e Domat (35), juntamente com o sobresselvano.

c) Mantogna, a sul de Plaun e à esquerda do Reno, que inclui, de sul a norte: Flerden e Portein (3), Sarn e Tartar (2) e Dalin e Prez (1), Cazas e Realta (8). Em alemão, esses falares são reunidos sobre a denominação de Heinzenbergisch.

d) Tumleastga, entre Thusis e Razen, à direita do Reno, que agrupa de norte a sul: Seglias e Scharans (10), Almen (9), Roten e Paspels (7), Giuvalta, Tumegl e Trans (6), Sched (5) e Veulden (4). Em alemão, esses falares são reunidos sob a denominação de Domleschgisch.

e) Schons, ao sul de Mantogna e Tumleastga, separado por áreas de fala alemã (Tschappina, Urmeins, Thusis, Sils i.D. e Mutten); inclui de sul a norte: à direita do Reno: Andeer (15), Pignia (16) e Ziraun (14); à esquerda do Reno: Clugin e Vargistagn (13), Donat e Lon (11), Maton (12). Os falares dessa região são conhecidos como Schamsisch.

f) Val Ferrera, ao sul de Schons, na fronteira italiana: Ferrera (17), Calantgil (18). 
Como se pode ver pelo Mapa 4, as áreas de Mantogna e Tumleastga são separadas do Schons e Val Ferrera por uma área de fala alemã, em que estão ainda muito visíveis os substratos romanche e do alemão valesiano formada por Tschappina, ${ }^{20}$ Urmeins, Thusis, Sils i.D. e Mutten.

MAPA 4: Área do subselvano

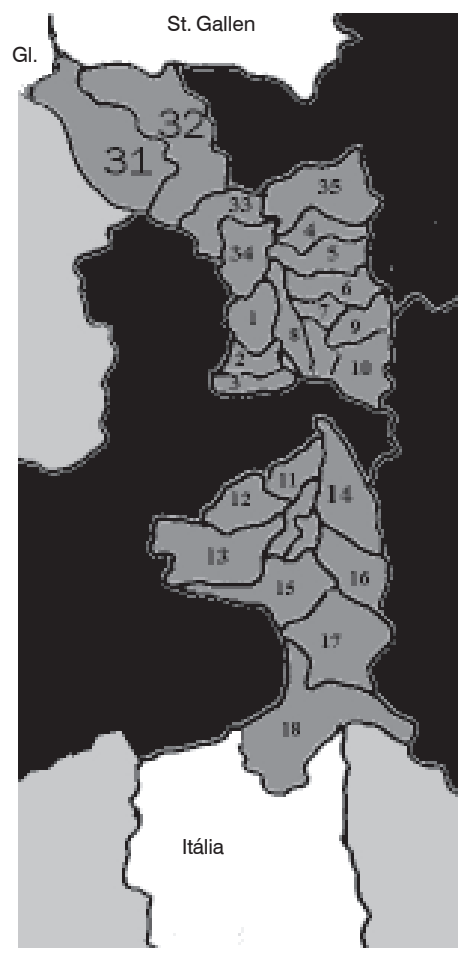

Nessa área, tradicionalmente atribuída ao subselvano, tem ocorrido, nos últimos tempos, um intenso decréscimo de uso desse falar romanche. Comparando a área do Reno anterior (sobresselvano) com a do Reno posterior (subselvano), observa-se que o primeiro grupo equivale a 49,2\% dos falantes de romanche nos Grisões, enquanto o segundo a apenas 2,6\%. $\mathrm{Na}$ área subselvana, o romanche é a língua que melhor domina 14\% dos habitantes do Plaun, 12\% nas demais regiões. Como língua falada na família, escola e/ou trabalho, chega a $27 \%$ no Plaun e $20 \%$ nas demais regiões e como língua compreensível, de 48\% do Plaun e 36\% das demais regiões. A única região em que a maioria da população

${ }^{20}$ JENNY. Wier und schii: dialektgschichtä va Tschappina. 
usa subselvano em detrimento do alemão é o lado esquerdo do Reno, na região de Schons. ${ }^{21}$ Do ponto de vista histórico, os textos em subselvano são mais antigos que os em sobresselvano: o primeiro documento é o catecismo de Daniel Bonifaci, intitulado Curt mussament "pequena cartilha", escrito no dialeto de Tumleastga (1601). Mais tarde, o subselvano imitou a escrita protestante do sobresselvano, sendo por vezes difícil a distinção entre as duas variantes em textos antigos. Somente no século XX (1916-1917) é que a literatura subselvana foi retomada. Sua ortografia atual é baseada em grafemas que podem representar vários sons distintos, dependendo do dialeto local, chamada Deckmantelorthographie, criada em 1943 por Giuseppe Tommaso Gangale e lançada no ano seguinte na Conferência de Scharans. Para o estudo do subselvano é indispensável o dicionário de Mani, ${ }^{22}$ que se baseia nas variantes da região chamada Sutselva Pintga "pequena Subselva": ou seja, Tumleastga, Mantogna e Schons.

A seguir traduz-se a mesma história apresentada para o sobresselvano:

La vualp eara puspe egn'eada fumantada. Qua â ella vieu sen egn pegn egn corv ca taneva egn toc caschiel ainten sieus pecel. "Quegl gustass a mei”, â ella tartgieu, ed â clamo agli corv: "Tge beal ca tei es! Scha tieus tgànt e aschi beal sco tia pareta, alura es tei igl ple beal utschi da tuts.”.

\subsection{Sobremirano}

O sobremirano (que seus próprios falantes denominam rumantsch, surmiran ou em alemão mittelbündnerisch ou surmeirisch) é usado por 4.500 pessoas na região dos Grisões

\footnotetext{
${ }^{21}$ GROSS et al. Rätoromanisch: facts and figures, p. 23-26.

${ }^{22}$ MANI. Pledari sutsilvan rumàntsch-tudestg tudestg-rumàntsch.
} 
Centrais (Mittelbünden). Da mesma forma que se usa o termo romanche renano ao conjunto formado pelo sobresselvano e subselvano, também a denominação romanche central é usada como nome genérico para o subselvano e sobremirano. O nome está associado a Meir (<lat. murum), nome de um caminho muito usado, à direita do desfiladeiro de Schyn (entre Vaz e Stierva). Assim, esse caminho ligava a região do Surmeir e a do Sotmeir, ou seja, o vale de Albula e Tumleastga. Costuma-se dividir o sobremirano em dois grupos geográficos em que aparece o termo ses "pedra" (< lat. saxum), que faz referência à Crap Ses, maciço rochoso próximo a Casti:

a) Sotses: região abaixo do Crap Ses (subgrupo denominado às vezes unterhalbsteinisch ou sutsettisch), ou seja, o vale de Albula, que inclui, de norte a sul, de oeste a leste: Vaz e Solas (1), Lantsch e Alvaschagn (2), Brinzauls (4), Surava (5), Alvagni (3). Mais a sul do Albula, na fronteira com o Surses estão, de oeste a leste, Solas já referida, Stierva (7), Mon (6) e Casti (10). A oeste do vale de Albula, está Filisur (17). Fala-se também sobremirano em Bravuogn, Latsch e Stogl, na área puter.

b) Surses: acima do Crap Ses (subgrupo denominado oberbalbsteinisch ou sursettisch). Bem ao sul, no passo de Güglia, estão Bivio (16), a sul, e Marmorera (15), a norte. Depois, seguindo o rio Gelgia, de sul a norte, até encontrar o Albula estão: à direita do Gelgia: Sour (19), Rona (13), Tinizong (18), Savognin (12), Cunter (11), do lado esquerdo: Mulegns (14), Parsonz (9), Riom (8) e Salouf (7).

O sobremirano equivale a $9,2 \%$ do romanche falado nos Grisões. Segundo Gross et al. (1996, p. 23-26), 32\% da população da área sobremirana reconhece essa variante como a língua que domina melhor. Tal valor sobe para $42 \%$ se se questiona qual é a língua falada na família, escola e/ou trabalho e para $59 \%$ ao se perguntar se é uma língua compreensível. Toda a área do Sotses (com exceção de Solas, Brinzouls, Mon e Stierva) já é área onde 
predomina a língua alemã. O mesmo se diz de Bivio e Marmorera. Contrastem-se a impressionante diferença entre $9 \%$ dos habitantes de Bivio, que informam ser o sobremirano a língua que domina melhor em oposição aos $82 \%$ de Salouf ou os 26\% dos habitantes de Vaz, que alegam usar o romanche na família, escola e/ou trabalho ao lado dos $91 \%$ da mesma aldeia de Salouf. ${ }^{23}$ Do ponto de vista histórico, o estabelecimento de uma escrita diferente da do sobresselvano e do subselvano se registra já em documentos religiosos do século XVII e principalmente XVIII. Decurtins ${ }^{24}$ traz um documento sobre confissões de bruxas, que se intitula $\mathrm{Da}$ chegl tgi streias on confesso "Sobre o que as bruxas confessaram". Muito interessante também é um documento trilíngue em que aparecem, lado a lado, palavras em italiano, em sobresselvano e em "romancio di Surset", datado de $1729 .{ }^{25}$ Normas ortográficas surgiram em 1896-1897 com o trabalho de Gion Candreia, mas a escrita atual segue a proposta por Giatgen Battaglia e Mena Wüthrich-Grisch, de 1939. Muito importante para o estudo do sobremirano são o dicionário de Ambros Sonder e Mena WüthrichGrisch (1970) e a gramática de Gion Peder Thöni. ${ }^{26}$

\footnotetext{
${ }^{23}$ GROSS et al. Rätoromanisch: facts and figures, p. 23-26.

${ }^{24}$ DECURTINS. Rätoromanische Chrestomatie, p. 1-18.

${ }^{25}$ DECURTINS. Rätoromanische Chrestomatie, p. 44-90.

${ }^{26}$ THÖNI. Rumantsch-Surmeir: grammatica per igl idiom surmiran.
} 


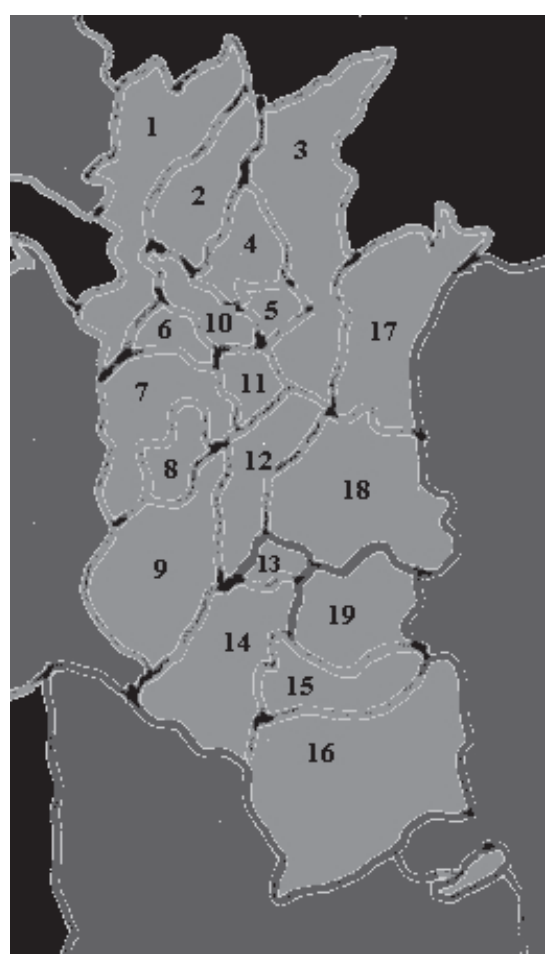

MAPA 5: Área do sobremirano

A mesma história da raposa será transcrita abaixo.

La golp era puspe eneda famantada. Co ò ella via sen en pegn en corv tgi tigniva en toc caschiel an sies pecal. "Chegl am gustess", ò ella panso, ed ò clamo agl corv: "Tge bel tgi te ist! Schi ties cant è schi bel scu tia parentscha, alloura ist te igl pi bel utschel da tots.".

\subsection{Puter}

O puter (que se denominam rumauntsch, ladin, putèr ou em alemão oberengadinisch) é falado por 3.000 pessoas ao longo do rio En (=Inn) na Engiadin'Ota entre a Lombardia e as regiões de fala sobremirana e valáder, exceto em Val Poschiavo, onde só há o lombardo. 
Fala-se puter em:

a) Val Bregaglia, onde é falado juntamente com o lombardo (Vicosoprano, Stampa).

b) Val Albula, onde se fala puter junto com o sobremirano. De oeste a leste: em Stogl, Latsch e Bravuogn (1). Em Bivio, além do sobremirano, fala-se também puter e lombardo. O falar de Bravuogn revela, em muitos aspectos, uma forma intermediária entre o sobremirano e puter.

c) Engiadin'Ota: subindo o En, de sul a norte: Fex e Segl (11), Silvaplauna (10), S Murezzan (9), Schlarigna (8), Samedan (7 e 12) e Bever (6). Ao lado direito, entre Schlarigna e Samedan, num afluente do En que nasce em Poschiavo, está Puntraschigna (13). Subindo ainda mais o En, encontram-se, de sul a norte, La Punt Chamues-ch (4), Madulain (5), Zuoz e S-chanf (2), Cinuos-chel e Brail (3).

O puter é, ao lado do subselvano, uma das variantes mais ameaçadas de extinção. Equivale a 9,4\% dos falantes de romanche no cantão dos Grisões. É considerada a língua que $24 \%$ dos habitantes da área tradicional dominam melhor (em S. Murezzan, apenas 6\%). Na família, escola e/ou trabalho, $44 \%$ dizem usar puter (contra 14\% em S. Murezzan). No entanto, é compreensível para 69\% da área discriminada (em S. Murezzan, 55\%). Em todo o território puter, mais do que em outras variantes, é o alemão a língua que predomina, exceto em Cinuos-chel e Brail. ${ }^{27} \mathrm{O}$ puter é a variante com documentação mais antiga. O primeiro texto data de 1527, o poema histórico-político La chianzun dalla guerra dalg chiasté da Müs ["Canção da guerra do Castelo de Muso"], de Gian Travers, seguido das obras de Jachiam Bifrun: o catecismo üna cuorta et christiauna fuorma "Uma cartilha pequena e cristã" (1552) e a mais antiga tradução da Bíblia, L'g Nuof Sainc Testamaint (1560). Para o estudo do puter, é muito importante o uso dos

\footnotetext{
${ }^{27}$ GROSS et al. Rätoromanisch: facts and figures.
} 
dicionários de Reto R. Bezzola e Rudolf O. Tönjachen ${ }^{28}$ (alemãoengadino) e Oscar Peer $^{29}$ (engadino-alemão), além da gramática de Gian Paul Ganzoni (1983). Essas obras refletem os esforços do início do século XX no sentido de atualizar as ortografias tradicionais.

Segue-se, com a finalidade de ilustrar, a mesma história já apresentada nas outras variantes:

La vuolp d'eira darcho üna vouta famanteda. Co ho'la vis sün ün pign ün corv chi tgnaiva ün töch chaschöl in sieu pical. "Que am gustess", ho'la penso, ed ho clamo al corv: "Che bel cha tü est! Scha tieu chaunt es uschè bel scu tia apparentscha, alura est il pü bel utschè da tuots.”.

MAPA 6: Área do puter

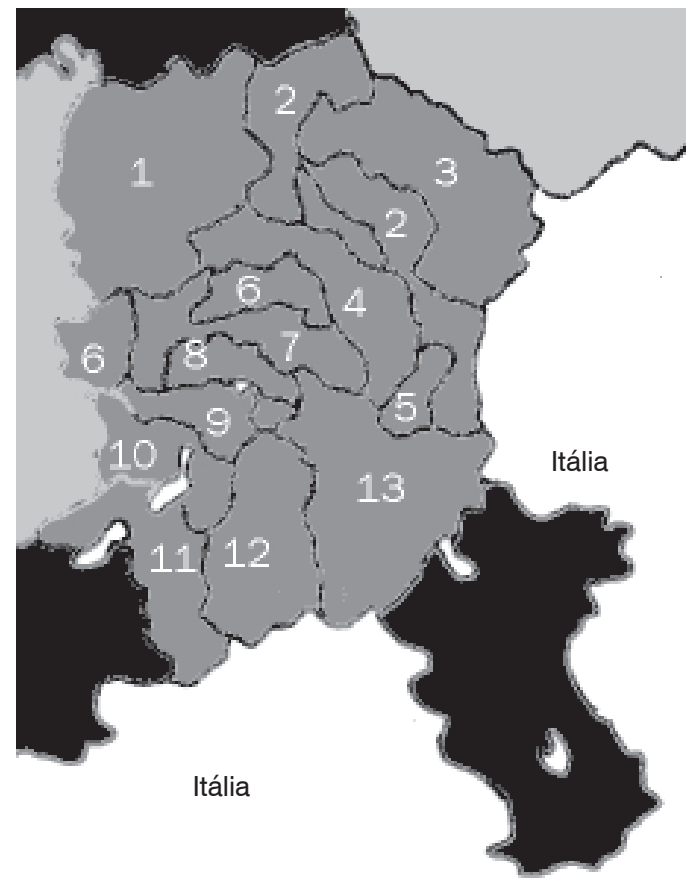

${ }^{28}$ BEZZOLA; TÖNJACHEN. Dicziunari tudais-ch-ladin.

${ }^{29}$ PEER. Dicziunari rumantsch ladin-tudais-ch. 


\section{5. Valáder}

O valáder (conhecido localmente como rumantsch, ladin, vallader ou, em alemão, unterengadinisch) é falado por 6.000 pessoas ao longo do rio En na fronteira da Áustria e da Itália, à direita do Prätigau, a norte da zona de fala puter, com exceção de Samnaun. Fala-se valáder nas regiões da:

a) Engiadina Bassa é uma região que, acompanhando o En de sul a norte, se subdivide em:

- Val Sura, que inclui Zernez (11), Susch (10), Lavin (9), Guarda (7), Ardez (8) e Ftan (4).

- Val Suot, que inclui Tarasp (6), Scuol (5), Sent, Vna e Ramosch (2), Strada, Martina e Tschlin (1).

b) Val Müstair, entre o Oberpaß e Venosta, incluindo, de oeste a leste: Tschierv (12), Lü (14) e Müstair (16), a sul do Rom: Fuldera (15), Valchava (13) e Santa Maria i. M. (17). A variante do Val Müstair é muitas vezes denominada jauer.

Em Livigno, na Lombardia italiana, o valáder mistura-se com o italiano.

O valáder é, depois do sobresselvano, a variante mais usada nos Grisões: 17, 7\% dos falantes de romanche usam valáder. Em toda área tradicional, é a língua que 68\% dos falantes domina melhor. Quando se pergunta sobre qual língua se usa em casa, no emprego e/ou escola, o valor chega a $81 \%$. Além disso, $89 \%$ dos habitantes da região dizem entender o valáder. Em Tarasp, no entanto, o alemão é a língua mais corrente. ${ }^{30} \mathrm{O}$ valáder não tem textos tão antigos quanto o puter, no entanto, as duas normas escritas se estabeleceram desde o século XVI. O primeiro texto de que se tem notícia é o Cudesch da psalms, de 1562, de autoria de Durich Chiampel. Para o estudo do valáder são usados os mesmos

\footnotetext{
${ }^{30}$ GROSS et al. Rätoromanisch: facts and figures, p. 23-26.
} 
dicionários já citados de Reto R. Bezzola e Rudolf O. Tönjachen ${ }^{31}$ (alemão-engadino) e Oscar Peer ${ }^{32}$ (engadino-alemão), além da Grammatica ladina de Gian Paul Ganzoni. ${ }^{33}$ Em francês se encontra o excelente manual de Ricarda Liver. ${ }^{34}$

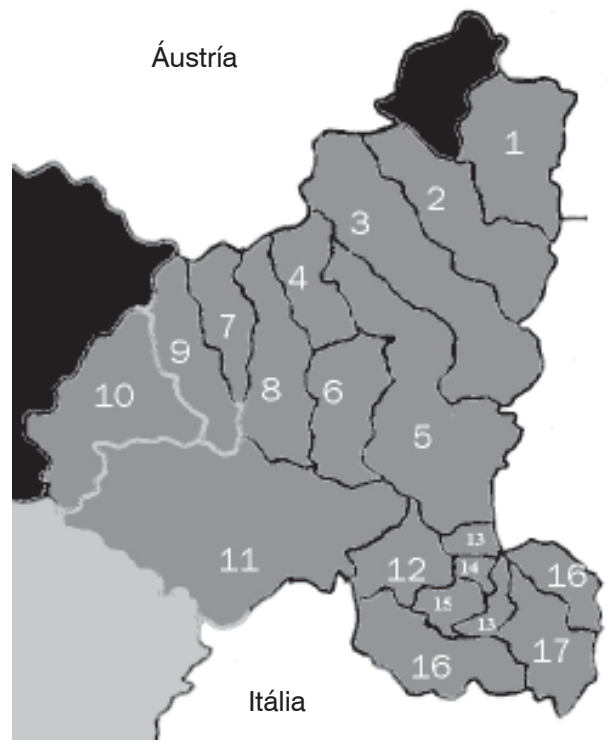

MAPA 7: Área do valáder

As diferenças regionais do valáder são um pouco mais acentuadas do que no puter. A seguir, a mesma história:

La vuolp d'eira darcheu üna jada fomantada. Qua ha'la vis sün ün pin ün corv chi tgnaiva ün toc chaschöl in seis pical. "Quai am gustess", ha'la pensà, ed ha clamà al corv: "Che bel cha tü est! Scha teis chant es uschè bel sco tia apparentscha, lura est il plü bel utschè da tuots.".

\footnotetext{
${ }^{31}$ BEZZOLA; TÖNJACHEN. Dicziunari tudais-ch-ladin.

${ }^{32}$ PEER. Dicziunari rumantsch ladin-tudais-ch.

33 GANZONI. Grammatica ladina: grammatica sistematica dal rumauntsch d'Engiadin'Ota per scolars e creschieus da lingua rumauntscha e tudas-cha.

${ }^{34}$ LIVER. Manuel pratique de romanche sursilvan-vallader.
} 


\subsection{Romanche grisão}

O romanche grisão não é o proto-romanche, ou seja, a língua única que teria dado origem às cinco variantes suíças, acima descritas, mas uma construção artificial, idealizada por Heinrich Schmid. ${ }^{35} \mathrm{O}$ objetivo não é eliminar as variações regionais, mas salvar o romanche da extinção, desenvolvendo, assim, uma única norma culta escrita paralela às variantes, que passariam a ser apenas faladas, da mesma forma que o alemão oficial (Hochdeutsch) sobrevive como língua oficial escrita do ensino, da literatura e da imprensa ao lado do alemão suíço (schwyzertüütsch), basicamente falado e fragmentado numa quantidade incrível de dialetos (que, curiosamente, estão se fundindo cada vez mais numa koiné sem correr risco de extinção como os dialetos da Alemanha). Desde que Schmid idealizou o romanche grisão como língua escrita, boa parte do jornal La Quotidiana se encontra já escrito nessa variante e há campanhas para iniciá-lo nas escolas, no rádio, na TV e na internet. A aceitação tem demorado menos do que se imaginou. Essa proposta não foi a primeira: citem-se como precursoras as tentativas do padre beneditino P. Placidus a Spescha, o "rumantsch fusionau" de Antoni Bühler e o "interrumantsch" de Lezza Uffer. Diferentemente das propostas anteriores, o romanche grisão tem sido usado em maior escala, pois os falantes têm hoje mais consciência de que suas variantes estão em processo de extinção, mas, mesmo nos meios acadêmicos, o que se encontra é a presença do alemão preenchendo essa lacuna. $\mathrm{Na}$ verdade, o romanche grisão é uma koiné que foi "acelerada", que talvez nunca ocorresse senão artificialmente. Os argumentos para a existência de uma única forma escrita para o romanche são fortes: no atual estágio, o romanche se fragmenta em cinco normas distintas, embora tenha apenas alguns milhares de falantes. As demais línguas da Suíça

${ }^{35}$ SCHMID. Richtlinien für die Gestaltung einer gesamtbündnerromanischen Schriftsprache Rumantsch Grischun. 
que têm status oficial (e não têm menos variantes regionais) utilizam de uma única norma culta para milhões de falantes. Além disso, como se pôde observar nos parágrafos anteriores, uma criança que vá aprender a escrever na sua variante regional, não terá menos dificuldade do que se aprendesse em romanche grisão, uma vez que essas variantes regionais são também máscaras de uma fragmentação mais profunda, evidente nas chamadas Deckmantelorthographien, como no subselvano e sobremirano. Chega-se, dessa forma, à impressionante conclusão de que se trata, portanto, de uma única língua, tão fragmentada quanto qualquer outra língua europeia, que tem cinco normas cultas tradicionais.

A base do romanche grisão é o princípio da forma mais usada nas variantes sobresselvana, sobremirana e valáder (que, como se viu, são as mais faladas). A palavra "coisa" se diz chaussa em romanche grisão, baseado no srs. caussa, no val. chosa e no srm. tgossa. Schmid, por seguir esse princípio, não leva em conta, a não ser para efeito de decisão, as formas das variantes mais ameaçadas: o put. chosa e do sts. tgossa. No entanto, apesar da escrita padronizada e tradicional para cada variante, observa-se que mesmo em algumas áreas em que há o, o ditongo au persiste na fala. É o caso de grande parte área subselvana, além de aldeias do sobremirano (Mantogna) e do valáder (Lavin, Ardez e Ftan). Em outras áreas, a pronúncia pode ser com [o] fechado (em Sarn, na região subselvana de Mantogna; no valáder de Tschlin) ou com [॰] aberto (em Veulden, na região subselvana de Tumleastga; em Lon, na região subselvana de Schons; no sobremirano de Savognin e de Lantsch e no puter de S-chanf). Também apesar da escrita $\operatorname{com} c$, diz-se ['clawsə] no sobresselvano de Tujetsch. Noutras áreas do valáder (a saber, no Val Münster e em Scuol-Tarasp), a pronúncia é ['cja:sə] e, no puter se diz ['cije:sə], como em Marmorera e Bivio (também era assim no valáder de Susch).

Em nenhum momento, Schmid propôs inovações ortográficas radicais como a eliminação das consoantes geminadas ou a invenção de grafias novas para situações complicadas em 
todo o romanche, como por exemplo, para o trígrafo $s c h$, com o intuito de diferenciar os valores [S] e [3]. Embora uma medida assim facilitasse para o estrangeiro que quisesse aprender o idioma, seria de dificil aceitação para os próprios falantes de romanche. Para aplicar o princípio da maioria, não se baseou apenas nas convenções tradicionais da língua escrita, mas também na extensão do fenômeno territorial linguístico no número absoluto de pessoas que efetivamente falam a variante, pois de nada adiantaria utilizar uma forma amplamente difundida em áreas em que o romanche já está praticamente extinto. Por exemplo, Schmid decidiu eliminar o ditongo $e i$ a favor do ditongo $a i$, apesar de este parecer mais frequente do que aquele: $a i$ é usado na escrita somente no engadino, enquanto $e i$ aparece nas formas escritas do sobresselvano e do sobremirano. Explica sua decisão com o fato de que também o sobremirano de Sotses pronuncia [aj] e que, no sobresselvano, o ditongo [aj] aparece em Lumnezia, Cadi, Tujetsch e Medel, apesar de se escrever sempre como ei (a pronúncia [ej] só aparece no Foppa). Na verdade, a maior parte da área retoromânica dos Grisões usa [aj], porém o escreve de formas distintas. Também observa que a grafia ei é ambígua e $a i$ não, uma vez que o engadino usa $\boldsymbol{e} i$ onde o sobresselvano e o sobremirano usam $e$; por outro lado, o sobremirano usa $e i[\mathrm{ej}]$ onde o sobresselvano e o valáder grafam $i$, além de um outro $e i$ [ $\varepsilon j]$ usado no lugar do sobresselvano $e i$ [aj] e do engadino ai (sem falar das áreas em que há endurecimento do ditongo, como já visto). Schmid levou, pois, em conta não o princípio da maioria nas formas escritas, mas nas formas faladas.

O princípio da maioria, porém, não foi usado às cegas, pois desconsiderou quando se tratava de uma forma sociolinguisticamente muito marcada. Levou em conta também a compreensibilidade do resultado dentro do sistema do romanche grisão. Por exemplo, abandona casos ambíguos, como * $l i$, em favor de lieu "lugar", forma obtida através do confronto do sobresselvano liug, do valáder $l o ̈$ e do sobremirano $l i$. A forma escolhida teria justificação 
histórica: lieu apoia-se em lieuc, que aparece em Steffan Gabriel sem o $-c$ final, que já se apocopou na maior parte das variantes atuais. Diante de uma multiplicidade de formas, a escolha equilibrada muitas vezes fica difícil. Também houve a preocupação de não se privilegiar demais uma variante, pois, se a saída muitas vezes era utilizar arbitrariamente uma variante em detrimento da outra, posteriormente essa escolha era balanceada, para que não houvesse a acusação de preferir-se uma variante a outra.

Observa-se nitidamente essa postura mediadora no seguinte problema:

- $\quad$ [ka], [ke], [ki], [ko], [ku] em sobresselvano e sobremirano grafam-se ca, che, chi, co, cu; em subselvano ca, ce, ci,co, $c u$; em valáder e puter ca, (c)ke, (c)ki, co, cu.

- $\quad\left[\mathrm{c}^{\mathrm{j}} \mathrm{a}\right],\left[\mathrm{c}^{\mathrm{j}} \mathrm{e},\left[\mathrm{c}^{\mathrm{j}} \mathrm{i}\right],\left[\mathrm{c}^{\mathrm{j}} \mathrm{o}\right],\left[\mathrm{c}^{\mathrm{j}} \mathrm{u}\right]\right.$ sobresselvano, subselvano, sobremirano seriam tga, tge, tgi, tgo, tgu; em valáder e puter cha, che, chi, cho, chu.

- A solução conciliadora de Schmid para o romanche grisão foi:

- $\quad$ [ka], [ke], [ki], [ko], [ku]: ca, che, chi, co,cu.

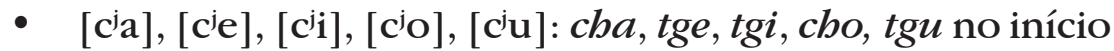
das palavras, mas tga, tge, tgi, tgo, tgu no meio. Para o som final $\left[\mathrm{c}^{\mathrm{j}}\right]$ se escreve sempre $\mathrm{tg}$ (como em sobresselvano, subselvano e submirano) e não $g$ ou $c h$ (como em valáder e puter).

A solução para a grafia do som [ $\left.\mathrm{c}^{\mathrm{j}}\right]$ se justifica da seguinte forma: esse som é grafado $\mathrm{tg}$ ou $\boldsymbol{c h}$ conforme a variante em questão. Um falante de valáder acharia estranho escrever $\mathrm{tg} \mathrm{em}$ casos que sempre escreve $\boldsymbol{c h}$ (por exemplo, *tgasa em vez de chasa) e um sobresselvano também acharia estranho, pois pronuncia casa. Optar radicalmente por $t g$ no início seria um erro, pois nem o sobresselvano nem o valáder aceitariam: para uma palavra sobresselvana iniciada com a sílaba [ka], como cantar "cantar" ou cauld "quente", um valáder teria [cja], respectivamente: 
chantar, chod. Portanto, ambos estariam acostumados a escrever com o grafema $c$ e uma ortografia para o romanche grisão do tipo tgantar ou tgaud seria estranha aos hábitos ortográficos de ambas as variantes. Por outro lado, escrever chasa, chantar, chaud lembrariam para os dois lados suas escritas regionais a que estão habituados. Quanto ao $\left[\mathrm{c}^{\mathrm{j}}\right]$ medial ou final, como aparece no sobresselvano spitgar "esperar" ou notg "noite" equivale a um [t] no valáder: spettar, not. Novamente, ambos têm o hábito de utilizarem do grafema $t$ e escritas como *spechar ou *noch nem sequer pareceriam romanche. A solução seria manter esse $t$ nas grafias spetgar, notg. Schmid então se pauta na proposta de Leza Uffer, que utiliza duas grafias para o mesmo som (contudo com uma regra extremamente simples), portanto, a funcionalidade da proposta do romanche grisão é minimizar as estranhezas de uma escrita artificial.

A proposta do romanche grisão faz, muitas vezes, uso da história interna das variantes desde o latim vulgar. Descartando os sons $\ddot{o}$ e $\ddot{u}$, restritos ao engadino, Schmid computa-os, no cálculo do princípio da maioria, como, respectivamente, $e$ e $i$. Assim, a palavra stgisa "desculpa" se montou a partir do srs. stgisa, do val. s-chüsa (lê-se ['sc'y:zə]) e do srm. stgeisa. As formas se diferem foneticamente apenas na vogal tônica, mas com a regra de equivalência $i=\ddot{u}$ contra $e i$, ou seja, duas ocorrências contra uma, prefere-se $i$. A multiplicidade das soluções na tabela vem da análise de palavra por palavra. Assim o lat. vaccam "vaca" origina srs. vacca, val. vacha, srm. vatga, portanto, rg. vatga (duas ocorrências do som [ $\left.\mathrm{c}^{\mathrm{j}}\right]$ contra uma do som [k]), mas outra palavra, foneticamente muito próxima, lat. buccam "boca" origina srs. bucca, val. bocca, srm. bucca, daí o rg. bucca. Não é incomum resultar, pela aplicação do princípio da maioria e da regra de equivalência, uma forma já existente numa das variantes. Assim, "livro" se diz cudesch no romanche grisão, como no valáder (cf. srs. cudisch, srm. codesch), mas "sol" se diz rg. sulegl como no sobresselvano (cf. val. sulai, srm. suglegl). Também pode ocorrer que da comparação 
de variantes se crie uma palavra diferente de todas as existentes nas variantes, por exemplo, "queijo" se diz rg. chaschiel (cf. srs./ srm. caschiel, val. chaschöl) ou "ganhar", que é rg. gudagnar (srs. gudignar, val. guadagnar, srm. gudagner). Observe que cada sílaba passou, independentemente, pelo princípio da maioria: $g u \times g u a$ $+d a \times d i+$ gnar $\times$ gner. Por causa dessa postura de equilíbrio, a proposta de Schmid difere de outras fracassadas, que postulavam um maior radicalismo nas regras. Tentativas de equiparar a norma oficial a uma das cinco variantes, como foi a de se usar o sobremirano como variante oficial do romanche, também não deram certo, principalmente pelo fato de o sobremirano ter formas foneticamente muito marcadas para os falantes das variantes mais faladas (sobremirano e valáder). $O$ fracasso das propostas de padronização, durante o século XIX, para as variantes occitanas do sul da França, também padece do mesmo problema, uma vez que se pautavam puramente na fonética, ignorando não somente a extensão dos fenômenos linguísticos e sua efetiva utilização, mas também toda a tradição escrita regional.

A mesma história da raposa, apresentada para as demais variantes, ficaria da seguinte maneira em romanche grisão:

La vulp era puspè ina giada fomentada. Qua ha ella vis sin in pign in corv che tegneva in toc chaschiel en ses pichel. "Quai ma gustass", ha ella pensà, ed ha clamà al corv: "tge bel che ti es! Sche tes chant è uschè bel sco tia parita, lur es ti il pli bel utschè da tuts.".

Bastaria uma leitura atenta nas considerações que se fizeram em cada variante para observar que o princípio da maioria foi usado à risca na história da raposa. Para o estudo do romanche grisão é imprescindível o dicionário de bolso, que tem linhas gerais de gramática, publicado pela editora Langenscheidt e organizado por George Darms, Manfred Gross e Anne-Alice Dazzi. ${ }^{36}$ A Lia Rumantscha

${ }^{36}$ DARMS; GROSS; DAZZI. Wörterbuch rätoromanisch-deutsch deutschrätoromanisch. 
tem feito amplos esforços para a divulgação do romanche grisão. George Darms, Manfred Gross e Anne-Alice Dazzi ${ }^{37}$ organizaram, assim, o Pledari Grond (em disquetes, 1995) e Gieri Menzli ${ }^{38}$ desenvolveu um método com fitas cassete intitulado Curs da rumantsch grischun (1988). É importante observar que o Institut Rumantsch Grischun de Chur não trabalha com essa norma, antes seu objetivo principal é a confecção do Dicziunari Rumantsch Grischun, uma obra colossal, ainda inacabada, idealizada no século XIX por Robert von Planta e que continua até os dias de hoje, como parte de um grande projeto dos Idiotika suíços (ao lado do Wörterbuch der schweizerdeutschen Sprache, Glossaire des patois de la Suisse romande e do Vocabolario dei dialetti della Svizzera italiana). Além disso, há muitos folhetos informativos sobre o romanche grisão em vários idiomas, com a finalidade de conscientizar os falantes de sua necessidade. Recentemente o jornal La Quotidiana anunciou (17/07/1998) que o romanche grisão estava sendo implementado nas escolas de Vaz (região sobremirana). Sobre a aceitação do romanche grisão leia-se Diekman. ${ }^{39}$

\section{Os grupos na Itália}

\section{1. O ladino}

O ladino dolomítico é um grupo de variantes faladas por cerca de 30.000 pessoas nos vales que irradiam do Maciço de Sella, a sudeste de Bressanone (=Brixen), circundado pelo alemão tirolês e dialetos italianos lombardo, trentino e vêneto, afora regiões espalhadas a oeste e leste. O alemão tirolês difere dos dialetos alemães

\footnotetext{
${ }^{37}$ DARMS; GROSS; DAZZI. Pledari grond tudestg-rumantsch rumantsch-tudestg.

${ }^{38}$ MENZLI. Curs da rumantsch grischun .

39 DIEKMAN. Probleme und Aspekte von Kodifizierungsbemübungen des Bündnerromanischen und Bericht über eine Umfrage zur Rezeption und Akzeptanz des Rumantsch Grischun als gesamtbündnerromanischer Schriftsprache.
} 
falados na Suíça (genericamente chamados de schwyzertüütsch), pois estes são do grupo alamânico, enquanto aquele é do grupo bávaro, como os dialetos da Bavária alemã, da Áustria, Liechtenstein e Samnaun, nos Grisões, a norte da área valáder. As variantes do ladino se encontram repartidas, desde 1923 e 1927, por motivos políticos, em três províncias italianas.

Esse grupo se subdivide em vários falares distintos:

a) Grupo atesino do Sella (região do Alto Ádige, província italiana de Bolzano ou Tirol meridional), a leste do Isarco e a sul do Rienza. Trata-se da área em que o ladino é mais vivo e onde há mais empenho na sua preservação. Fala-se ao lado do italiano (oficial ou variantes trentinas de Branzoll, Pfatten e Salurn) e principalmente do alemão tirolês. Esse grupo compõe-se de:

- Val Badia, a nordeste do maciço, onde estão, de sul a norte, La Val, Calfosch, La Ila, Corvara, S. Ciascian, S. Linert, S. Martin de Tor. A variante usada ali é o badioto (al. Gadertalisch). Na região setentrional encontra-se La Pli, Al Plan de Mareo, Rina, S. Vigil, cuja variante, muito próxima do badioto, se chama marebano (em alemão, Ennebergisch). As duas variantes somam 10.000 falantes.

- Val Gherdëina, a oeste da região do badioto, a noroeste do maciço. Ali se encontra de oeste a leste, Urtijëi, Bula, Sta. Cristina, Sëlva. Sua variante se denomina gardenês (em alemão Grödnerisch), falada por 8.000 pessoas.

b) Grupo trentino do Sella, de substrato atesino mas já bastante marcado desde o século XII pelos dialetos italianos do Trento, falados a sul do Avisio e do vale do Fiemme. Fala-se ladino no:

- Val Fascia, a sudoeste do maciço de Sella, ao longo do Avisio, onde se encontram, de sul a norte: Moena, Vich, Moncion, Delba, Ciampedel, Mazin, Cianacëi. Ali se fala ofassano, com suas três variantes: o moenat, o brach e o cazet, que juntas é a língua de 7000 pessoas. O ladino convive nessa região apenas com o dialeto italiano trentino. 
c) Grupo agordino do Sella, na província de Belluno, também de substrato atesino, mas com influência do italiano belunês desde o século XI. A influência do vêneto se fez sentir mais tarde e os dialetos italianos ao longo do Cordevole formam um verdadeiro degradé de formas, de modo que, desde Ascoli, usam-se os termos ladino-vêneto para dialetos italianos agordinos setentrionais (Caprile, Pescul, S. Maria de la Grazie, Alleghe, S. Tomaso) e agordinos centrais de Cencenighe e do Vale de Bióis (Vallada, Caviola, Falcada e Forno di Canale) e vêneto-ladino para os dialetos de La Valle e agordino meridional (Agordo, Taibon, Voltago, Frassenè, Rivamonte, Tiser, Gosaldo). Fala-se ladino no:

- Fodom, entre o fassano e ampezzano, região central, que abarca o próprio maciço e a área imediatamente a sudeste. Ali estão, de norte a sul, Reba, Ornela, Larcionei, Pieve de Livinallongo e Colle Sta. Lucia. Sua variante também se chama fodom (em alemão, Buchensteinisch), que é falada por 3.000 pessoas. Fala-se o mesmo ladino também em Laste e Rocca Pietore, segundo Pellegrini, ${ }^{40}$ que coloca o falar de Colle Sta Lucia junto com agordino setentrional.

d) Grupo ampezzano, de substrato cadorino e superstrato belunês e vêneto. Cerca de 3.000 pessoas falam o ampezzano no Val Ampëz, também na província de Belluno, região a leste do maciço de Sella, separada dele pelo Fodom. Ali se encontra Andrac e Cortina d'Ampezzo, cujo falar ladino se encontra bastante ameaçado, uma vez que o italiano é a língua mais falada. A sul, no Zoldo, os dialetos italianos zoldanos trazem traços ladinos: os dialetos italianos de S. Vito di Cadore e Vodo são muito próximos do ampezzano.

e) Grupo cadorino, grupo do Alto Piave que historicamente pode se considerar como intermediário entre o ladino e o friulano cárnico. O superstrato vêneto data do século XV. Fala-se ladino

\footnotetext{
${ }^{40}$ PELLEGRINI. Saggi sul ladino dolomitico e sul friulano, p. 11-268.
} 
em Oltrechiusa e, a leste, em Comelico, cerca de 10.000 pessoas falam uma variante comumente referida como comelicano. Mais a sul, a leste do Zoldo, na área friulana, no Vale de Vaiónt (Erto, Claut, Cimolais) fala-se uma forma intermediária entre o ladino, o friulano e o vêneto-belunês A variante de Erto foi estudada por Gartner em 1892.

f) Grupos solandro e nonês, distantes da região do Sella, a oeste, juntamente com dialetos italianos trentino e o lombardo, há comunidades que falam uma variante ladina no Val di Sole (sobretudo Fondo), ao longo do rio Noce, e no Val di Nòn. Em alemão são referidos respectivamente como Sulzbergisch e Nonsbergisch ou Anaunisch.

Quanto à literatura especializada, há muito material para se estudar ladino, alguns muito atuais. Vale aqui ainda a já citada obra de Haiman e Benincà. ${ }^{41}$ Para o estudo do gardenês, recomendam-se métodos como o de Rut Bernardi et al ${ }^{42}$ ou gramáticas como a de Anderlan-Obletter. ${ }^{43}$ Para os falares do Val Fascia, o dicionário de Alessandra Dellantonio Tajina ${ }^{44}$ e o reeditado dicionário de brach de Hugo de Rossi. ${ }^{45}$ Para o ampezzano, os dicionários ladino-italiano de Enzo Croatto ${ }^{46}$ e italiano-ladino de Liotta Colle et al. ${ }^{47}$ Cite-se ainda, para a anfizona (termo cunhado por Ascoli para as variantes ladinas distantes de Sella), o dicionário de Gemo da $\mathrm{Col}^{48}$ para o dialeto de Cibiana de Cadore.

\footnotetext{
${ }^{41}$ HAIMAN; BENINCÀ. The Rhaeto-Romance languages.

${ }^{42}$ BERNARDI et al. Curs de gherdëina.

43 ANDERLAN-OBLETTER. La rujeneda dla oma: gramatica dl ladin de Gherdëina.

${ }^{44}$ TAJINA Dizionèr talian-fascian-talian.

${ }^{45}$ ROSSI. Ladinisches Wörterbuch - vocabolario ladino (brach).

${ }^{46}$ CROATTO. Vocabolario ampezzano.

${ }^{47}$ COLLE et al. Vocabolario italiano-ampezzano.

${ }^{48}$ DA COL. L'idioma ladino a Cibiana di Cadore.
} 
Textos antigos em ladino são escassos. O mais antigo é de 1631. Há uma proclama de 1703, o dicionário ladino de Bartolomei, de 1763 e um pequeno texto de inícios do século XIX. Por fim é muito conhecida a gramática de Micurá de Rü, de 1833.

Como muitas variantes são apenas faladas e somete dispõem de escritas baseadas em transcrições fonéticas e como este trabalho não tratará especificamente desse bloco, apenas algumas variantes serão apresentadas aqui, com a finalidade de mostrar algumas de suas diferenças (ortográficas, fonéticofonológicas, lexicais e morfossintáticas), em relação ao romanche.

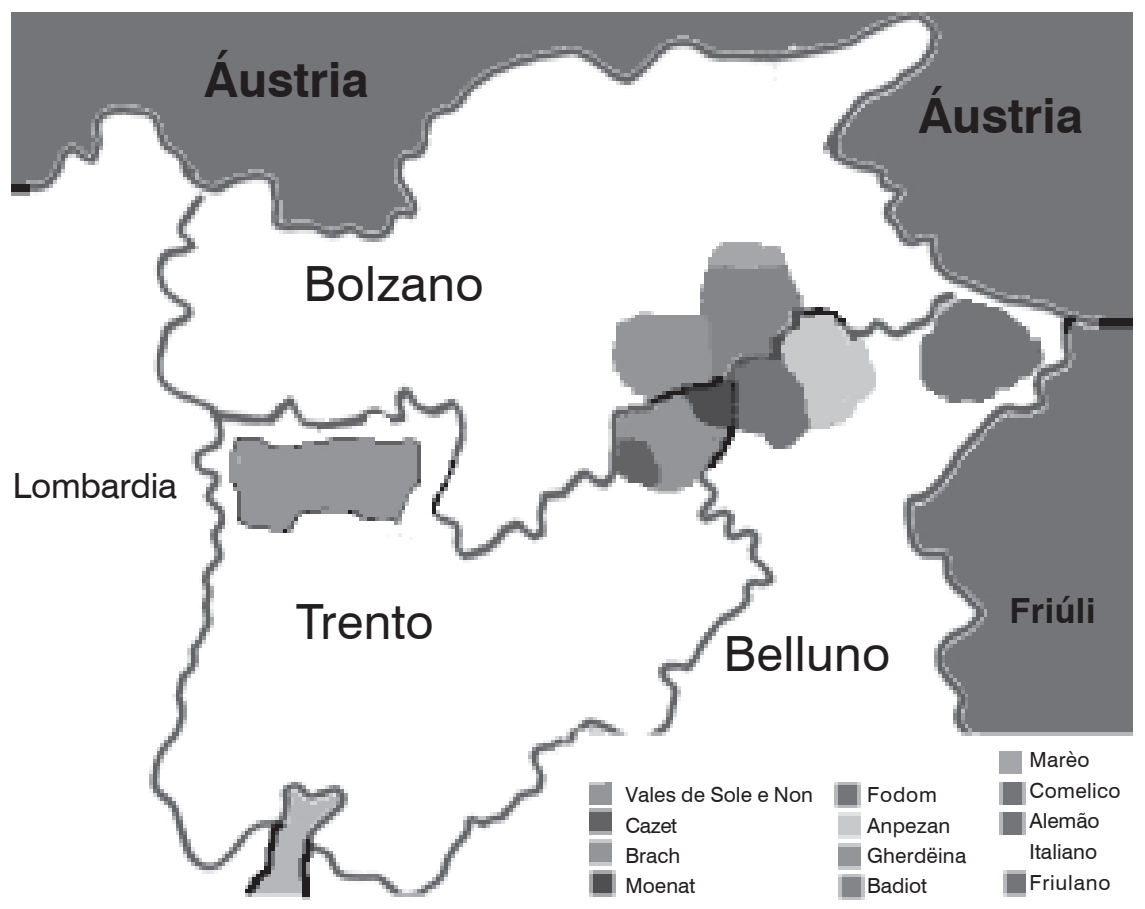

MAPA 8: Área do ladino

Com a finalidade de mostrar a diferença entre o ladino dolomítico e o romanche, assim como entre os falares do ladino dolomítico, a mesma história da raposa, contada acima será 
traduzida. ${ }^{49}$ Não se deterá na transcrição e comentários específicos sobre cada variante, portanto, limitam-se os comentários fonéticos de apenas duas variantes bem afastadas linguisticamente, scilicet, o gardenês e o ampezzano.

\section{Badioto:}

La olp â indô $n$ iade fan. Te chëra ara odü n corf sön $\mathrm{n}$ aidin, che se tignî $\mathrm{n}$ tòch de ćiajó tl bech. "Chël me savess bun", se ponsâra, y ti scraia al corf: "Tan bel che t'es! Sce to ćiantè é tan bel co che te ćiares fora, spo éste le plü bel de düci vicí."

\section{Marebano:}

La olp â endô $n$ iade fan. Te chëra ára odü en corf sön en aidin, co se tegnía en toch de ćiajó tal bech. "Chël mo sess bun", se ponsâl, y ti scraia al corf: "Tan bel che t'es! Sce to ćianté é tan bel co che te ćiares fòra, spo éste le plü bel de düći vicí."

\section{Gardenês:}

La bolp ova inò $n$ iëde fam. Te chëla ala udù $n$ corf sun $\mathrm{n}$ pinch che se teniva $\mathrm{n}$ toch de ciajuel tl bech. "Chël me savëssa bon" se pensòvela y ti sveia al corf: "Tan bel che t'ies! Sce ti cianté ie tan bel sciche tu cëles ora, pona ies tu 1 plu bel de duc i uciei."

\section{Fassano:}

La bolp aea, amò n'outa, fam e te chela l'à vedù n crot su $\mathrm{n}$ avez che se tegniva $\mathrm{n}$ toch de formai tel bech. "Chest vé me saessa dassen bon", la se à pissà, e la ge à cridà sù al crot: "Che bel che t'es! Se to ciantèr l'é

${ }^{49}$ Agradeço a Paul Videsott da Universidade de Innsbruck pelo envio das traduções. A Sabina Valentini, do Instituto Ladino "Micurà de Rü" pelo gardenês. A Nadia Valeruz, do Institut Cultural Ladin, pelo fodom e fassano. A Elisabetta Menardi, da Union di Ladins d'Ampezzo, pelo ampezzano. 
sci bel che tia parbuda, embendapò tu te es 1 più bel de duc i ucìe.".

\section{Fodom:}

La bolp l'ava ncora nviade fam. Nte chëla no $\mathrm{n}$ ala vedù $n$ còrf su nen avëz che se tegniva $n$ tòch de formai ntel bech. "Chël me savëssa chèro bon", la se pensáva, e la ié scraia al còrf: "Cotánt bel che ti t'es! Se tuo cianté 1 é coscita bel coche 1 é tua parbuda, nlouta t'es 1 plu bel de duc i uciei.".

\section{Ampezzano:}

Ra olpe r'aéa danoo fàme. In chera r'à vedù un cròo su un avedin, che'l se tienìa un tòco de forméi inze'l bèco. "Chéšto cà el me piajaràe pròpio", ra se pensàa e ra i craiàa al cròo: "Ce un bèl che tu te sôs! Se el to ciantà ' 1 é cosita un bel ce modo che te vardes fora, alóra š̀ che te sôs el pì bèl intrà dùte i uziéi”.

\section{Ladin Dolomitan:}

La volp ova endò $n$ iade fan. Te chela ála vedú $n$ corf sun $\mathrm{n}$ aidin, che se tegniva $\mathrm{n}$ toch de ciajuel tl bech. "Chel me savess bun", se pensòvela, y ti scraia al corf: "Tant bel che t'ies! Sce ti cianté é tant bel co che te ciales fora, spo ieste 1 plu bel de duc i uciei."

A primeira tentativa de unificação dos falares ladinos data de 1833. Essa tentativa foi feita por Nicolau Bacher, conhecido sob o pseudônimo de Micurá de Rü. Contudo, dado o sucesso do romanche grisão, o mesmo linguista idealizador daquela norma escrita, o prof. Heinrich Schmid, foi convocado para sugerir uma proposta de padronização também para o grupo grupo dolomítico. É impossível saber o que irá acontecer nesse caso, mas certamente a norma padronizada não terá aceitação tão rápida quanto na Suíça: a proposta é de 1998, as variantes dolomíticas estão separadas em três Estados diferentes, com legislações diferentes 
com respeito ao ensino da língua ladina. A noção de unidade é ainda mais tênue nesses grupos e seus contatos, mais difíceis. ${ }^{50} \mathrm{O}$ mesmo princípio da maioria foi utilizado, no entanto, diferentemente do caso do romanche grisão, em que três variantes foram comparadas (sobresselvano, valáder e sobremirano), o ladin dolomitan se fundamentou praticamentesobre todas as variantes mareo/badioto, gardenês, fassano (que inclui cazet, brach e moenat), fodom e ampezzano. Em muitos casos, a decisão é difícil. Não há uma solução única para lat. $-v$ - ou $v$-: lat. plovere "chover" se torna ld. plovei (mar. ploei, bad. plovëi, grd. pluëi, fas. plever fod. pluove amp. pioe), mas lat. juvenem "jovem" > ld. joen. Algumas vezes surge um $v$ - não etimológico, que passa ou não para o ladin dolomitan, como em lat. *omni > ld. vigni "cada" (mar., bad., fod. vigni, grd. uni, fas. ogne, amp. ogni) ou lat. ovum "ovo" > ld. uef (mad., bad. $\ddot{u}$, ghe. uef, fas. ef, fod. vuof, amp. vovo). Uma vez lançadas as orientações básicas de Schmid para a escrita, morfologia e sintaxe ladina, desenvolve-se atualmente um intenso trabalho para a normatização da escrita do ladino e têm trabalhado, para isso, tanto o Spell, equipe do Istitut Cultural Ladin "Majon di Fascegn", no Val Fassa, quanto a Universidade de Innsbruck, na Áustria.

\section{2. O friulano}

O grupo denominado ladino orientale, por Ascoli, diferentemente dos outros dois grupos (occidentale ou romanche e centrale ou ladino), forma um conjunto bastante compacto de falares, que arroga para si o status de língua românica independente, conhecido como friulano (ou furlan, como se autodenominam; em al. se diz Friaulisch). O friulano encontra-se separado do ladino

${ }^{50} \mathrm{O}$ mesmo prof. Schmid expressou sua dificuldade, alegando, em entrevista ao autor deste trabalho, que demorara seis meses para idealizar o romanche grisão e seis anos para o ladin dolomitan. 
dolomítico pelo vêneto e por falares ladinos com forte influência vêneta (conhecidos como ladino-vêneto ou vêneto-ladino). Falam friulano cerca de 500.000 pessoas na região de Friúli, entre o Vêneto, a Áustria, a Eslovênia e o Adriático, às margens do rio Tagliamento.

Os dialetos friulanos dividem-se, geograficamente em: (a) Além-Tagliamento; (b) Val Cellina; (c) Val Meduna; (d) Val del Cosa e Arzino; (e) Friuli central; (f) Baixo Friúli; (g) Zona das Colinas; (h) Pré-Alpes orientais; (i) Médio Tagliamento; (j) Gorizia; (k) Val Fella e Val Canale; (l) Carnia Orientale; (m) Val Degano; (n) Alto Gorto; (o) Alto Tagliamento.

A leste, suas fronteiras são Tarvisio, onde o friulano convive com o alemão e o esloveno, e Gorizia, onde também se fala esloveno e vêneto. Os friulanos utilizaram por muito tempo uma koiné de base vêneta, que funcionava como norma urbana, que ainda ganha terreno (Maniago, Spilimbergo, Pordenone, Udine, Cividale, Palmanova, Cervignano). Em Timau e Sauris predomina o alemão. Em Monfalcone, Duino, Abrisina, Grado fala-se vêneto e, próximo ao rio Livenza, uma variante mista vêneto-friulana é ouvida em Sacile, Portogruaro, Latisana, Caorle. Em Erto, fala-se ladino, hoje fortemente friulanizado, trazido certamente por imigração. $\mathrm{Na}$ fronteira com a Eslovênia há várias outras zonas em que o friulano convive com o esloveno.

Há grande número de publicações da Societât Filologjche Furlane a respeito do friulano e seus dialetos. Para o estudo do friulano padrão, no entanto, são essenciais a gramática de Giorgio Faggin, ${ }^{51}$ assim como os dicionários de Gianni Nazzi. ${ }^{52}$

Muito diferentemente do ladino, cujos textos, quando muito, remontam a um vocabulário badioto do século XVII, a tradição escrita do friulano é bem antiga. Também o romanche dispõe de textos antigos (fragmento pseudoagostiniano do século XII), mas

\footnotetext{
${ }^{51}$ FAGGIN. Gramatica friulana.

${ }^{2}$ NAZZI; NAZZI. Dizionario italiano-friulano friulano-italiano; NAZZI et al. Dictionnaire frioulan; français-frioulan-frioulan-français.
} 
diferente do grupo ocidental, a tradição friulana é ininterrupta. Desde o século XIII existem textos em friulano e a primeira poesia remonta ao século XIV, um poema intitulado Piruç myò doç ["Minha doce perinha"], encontrado no verso de uma ata notarial, conservado na biblioteca de Udine.

Como se fez com o ladino, aqui se apresenta a mesma história da raposa, que em friulano ficaria: ${ }^{53}$

La bolp e veve, ančemò une volte, fan e vè ca ch'e à viodût un corvat parsore di un pin ch'al veve un toc di formadi intal bec."Chest culì lu ğholdarès une vore", e à pensât e i à berlât al corvat: "Ce biel che tù tu sês! Se il to čhant al è tant biel come la tô infičhe, alore tu sês il plui biel di dučh ju ucei."

Apesar de o friulano variar também dialetalmente, a língua culta, baseada numa koiné criada espontaneamente ao longo dos séculos, é bastante uniforme, se confrontada com as cinco escritas tradicionais do romanche, no entanto, no século XX surgiram inúmeras propostas ortográficas, que contribuíram para trazer complicações e uma certa variação na escrita. ${ }^{54}$ Entre os problemas apontados, cite-se o uso de dígrafos que se afastam da ortografia italiana, que se sobrecarregam com um diacrítico chamado pipa, equivalente ao háček, do tcheco: $\check{c}, \breve{g}, \check{s}$. Contra essa forma de grafar se encontram aqueles que apoiam, por exemplo, as ortografias $c j, g j$ em vez de č $h, \breve{g} h$.

${ }^{53}$ Agradeço à Societât Filologjche Furlane pelo envio do texto, via fax, cuja ortografia adaptei.

${ }^{54}$ ILIESCU. Zur Normierung der Graphie des Friaulischen. 


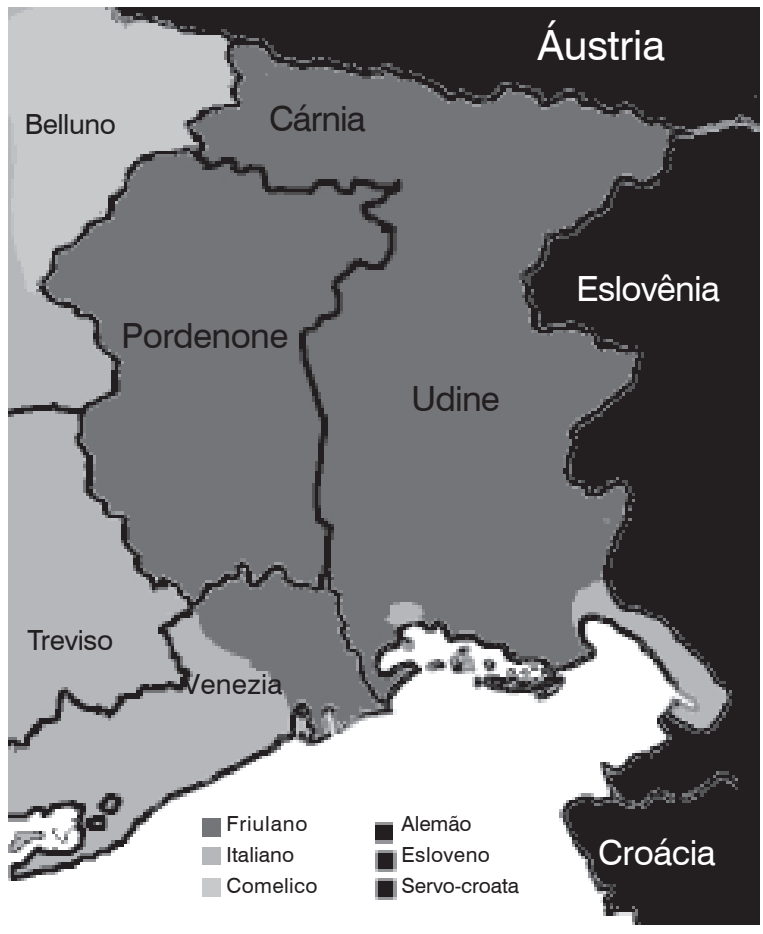

MAPA 9: Área do friulano

\section{A diglossia nos grisões}

Importa agora entender o papel do alemão suíço e do alemão oficial para a comunidade falante de romanche. Numa época antiga, só se falava uma variante do latim vulgar que, como visto, formava um feixe de isoglossas sem se diferenciar nitimamente de outros falares derivados do latim vulgar vizinhos e que sofria influências culturais e linguísticas vindas do sul, inicialmente de Roma, depois de Milão e Aquiléia. Esses falares, que, para simplificar, serão chamadas siplesmente de "romanche", 55

55 Como já discutido anteriormente, não se considera aqui uma forma intermediária entre o "latim vulgar" e esse "proto-romanche" já com variações regionais, aqui chamado simplesmente "romanche" (ou seja, um "proto-retoromânico"), que teria de se ter formado entre a queda do Império Romano (século V) e as primeiras incursões bávaras (século VI). 
conviviam paralelamente ao latim escrito. Essa situação remonta a uma fase original, uma vez que o romanche, fruto da derivação regional do latim vulgar, convivia sem grandes problemas ao lado do latim escrito, assim como em muitos lugares da România. Para entender os esquemas que se seguem, as formas faladas serão escritas na parte superior e as escritas na parte inferior:

\begin{tabular}{|c|}
\hline Romanche \\
\hline Latim \\
\hline
\end{tabular}

Ou seja, o esquema anterior deve ser lido como: o romanche era falado e o latim era escrito. Numa segunda fase, surge o bilinguismo: falares alamânicos passam a ser falados juntamente com o romanche, mas o latim continua a língua que se usa para escrever. Essa situação linguística começa já no século V e continuará, sem grandes alterações, até o século XIII, substituindo a anterior, sendo que o alamânico acabou por substituir o romanche em alguns lugares ou passou a ser falado lado a lado com o romanche em outros. Interessa aqui apenas o segundo caso.

\begin{tabular}{|c|c|}
\hline Romanche & Alamânico \\
\hline Latim medieval \\
\hline
\end{tabular}

Por volta do século XIII, surge uma nova situação: em alguns contextos, também o dialeto alamânico passou a ser escrito, agora sob a forma de alemão medieval. Essa nova forma escrita iniciou-se timidamente, mas tornou-se cada vez mais frequente e finalmente acabou por substituir o latim.

\begin{tabular}{|c|c|}
\hline Romanche & Alamânico \\
\hline Latim medieval & Médio-alto-alemão \\
\hline
\end{tabular}

No século XVI, o médio-alto-alemão acaba sendo, aos poucos, substituído pelo alemão luterano, que passa a ser o 
padrão da língua escrita moderna, o assim chamado "alemão oficial" (Schriftdeutsch / Hochdeutsch). Por exemplo, para "casa", em médio-alto-alemão escrevia-se buus, forma que, aliás, ainda hoje é usada na fala de toda Suíça germanófona, mas, após a Reforma Protestante, passa-se a escrever Haus, conforme a ditongação dos dialetos provindos da Alemanha. Da mesma forma, chind "criança" passou a ser escrito Kind. Também o vocabulário do alemão oficial é bem distinto do alemão suíço, sem falar da morfologia e da sintaxe. Em quase toda a Suíça, até os dias de hoje, estabeleceu-se uma diglossia: fala-se em alemão suíço (Schwyzertüütsch) e escreve-se em alemão oficial (Schriftdeutsch). Nos Grisões, onde o alemão não suplantou de todo o romanche, a situação era um pouco mais complexa, pois, ao lado do alemão suíço, falava-se romanche. Essa situação permaneceu assim em grandes áreas dos Grisões e é a situação de muitos falantes ainda hoje.

\begin{tabular}{|c|c|}
\hline Romanche local & Alemão suíço local \\
\hline Alemão oficial \\
\hline
\end{tabular}

Mas também desde o século XVI, em algumas áreas surge um outro fator de complicação: o romanche local passou a ser escrito e até o século XIX estarão formadas as cinco normas escritas do romanche (sobresselvano, subselvano, sobremirano, valáder e puter), que em alemão são chamados de Idiome. Para simplificar, os esquemas se referem, a seguir, a qualquer uma dessas formas como "romanche escrito" e o quadro se esquematiza assim:

\begin{tabular}{|c|c|}
\hline Romanche local & Alemão suíço local \\
\hline Romanche escrito & Alemão oficial \\
\hline
\end{tabular}

Vale observar que o alemão suíço pode ser de dois tipos: o primeiro é o alemão suíço renano, da qual a variante de Cuira (Churerdeutsch) é a fonte para a formação de uma koiné do alemão suíço dos Grisões (Bündnerdeutsch) e o segundo é o alemão suíço valesiano (Walserdeutsch) transplantado nos Grisões 
por volta do século XIV. Para complicar ainda mais, atualmente surgiu o romanche grisão (rumantsch grischun) como forma suprarregional de romanche escrito, que já é de domínio ativo de muitos.

\begin{tabular}{|l|l|}
\hline Romanche local & Alemão suíço local \\
\hline $\begin{array}{l}\text { Romanche escrito } \\
\text { Romanche grisão }\end{array}$ & Alemão oficial \\
\hline
\end{tabular}

Observe-se que esses esquemas demonstram, na verdade, os contatos linguísticos em que o falante tem participação ativa (falar e escrever). Não se fala aqui de situações passivas (entender e ler), que resultaria em esquemas mais complexos, porém, mais próximos do indivíduo. A situação pode se tornar ainda mais complicada, uma vez que um indivíduo pode entender duas ou mais variantes do romanche, assim como do alemão suíço, ou ler/ entender o italiano ou francês. Os esquemas apresentados mostram, portanto, situações que dizem mais respeito a estudos sociolinguísticos do que propriamente psicolinguísticos. Portanto, na realidade, em muitas regiões, o romanche se encontra apenas em situação passiva, sendo pouquíssimo falado no dia a dia do indivíduo (às vezes só falado com os pais ou com algum amigo). Outras vezes, seu uso é um pouco mais amplo (no emprego, com um número maior de conhecidos, etc.). O estudo de Solèr ${ }^{56}$ é bem esclarecedor nesse ponto: o autor contrasta a comunidade sobresselvana de Lumbrein, onde 99,7\% dos habitantes (cerca de 400) falam romanche, com outras duas subselvanas de Prez e Sarn (cada uma com cerca de 150 habitantes) em que, respectivamente, $42,7 \%$ e $9,9 \%$ "se consideram" romanches. Na comunidade de Lumbrein, a língua corrente é o sobresselvano, mas todos sabem

${ }^{56}$ SOLÈR. Sprachgebrauch und Sprachwandel: eine theoretische Faktoranalyse und die Pragmatik der Sprachbehandlung bei den Rätoromanen von Lumbrein mit einem Vergleich der Germanisierung in Präz und Sarn. 
alemão suíço e alemão oficial (salvo alguns indivíduoss, que só dominam uma das variantes). Nesses casos, detectaram-se interferências do romanche no alemão, como por exemplo, uma reestruturação das vogais longas e breves. ${ }^{57} \mathrm{O}$ domínio do alemão é resultado do contato com os turistas, com vendedores que lá chegam e com visitas de parentes, falantes de alemão (genros, noras, tios, sobrinhos). Usam seus conhecimentos de alemão quando se casam com um falante de alemão ou quando precisam se deslocar até Chur ou Glion, para comprar sapatos, livros, ir ao cinema ou ao dentista, sem falar do contato que têm com essa língua durante o serviço militar, vendo televisão ou ouvindo rádio. Contatos com o alemão escrito ocorrem o tempo todo, por meio de correspondências, jornais, livros de literatura e livros técnicos, prospectos, catálogos, indicações de itinerários, catálogo telefônicos, livros de receita, embalagem, livros de oração, obras de consulta, no passaporte, em atos jurídicos, em solicitações etc. É difícil imaginar que, nesse contexto, o alemão seja sentido como "língua estrangeira". A primeira etapa do romanche grisão tem sido atuar nessa área do alemão escrito, substituindo-o, a fim de se estabelecer uma diglossia romanche grisão/ falar local como ocorre, nas áreas germanófonas, com alemão oficial/alemão suíço. Dito doutra forma, há uma preocupação em tornar o romanche "visível". Veja a seguinte situação, descrita em Solèr: ${ }^{58}$

\footnotetext{
${ }^{57} \mathrm{O}$ alemão tem distinção fonológica entre vogais longas e breves. O romanche local, em geral, tem apenas uma distinção fonética, motivada por contexto fônico: as vogais tônicas tornam-se longas em posição final e após consoantes sonoras, /h/, /s/ e / / . Na verdade, quando há interferência do romanche sobre o alemão, o romanche perde $\mathrm{o}$ valor fonológico das vogais longas alemãs e reinterpretaas segundo o contexto fônico (WEINREICH. Languages in contact, p. 15-16)

${ }^{58}$ SOLÈR. Sprachgebrauch und Sprachwandel: eine theoretische Faktoranalyse und die Pragmatik der Sprachbehandlung bei den Rätoromanen von Lumbrein mit einem Vergleich der Germanisierung in Präz und Sarn, p. 9. (Tradução nossa)
} 
A mulher, falante de alemão, havia colhido amoras silvestres, que ela colocou em frente de suas colegas para escolher. A mulher romanche que está falando diretamente com ela, usa alemão, enquanto as outras deliberam umas com as outras em romanche sobre as amoras e o que seria feito com elas. Uma moradora de Lumbrein me pediu em romanche, para que eu desse uma olhada nas amoras, a fim de separá-las. A mulher que as colheu me explicou, em alemão, onde era o local em que as achou e respondeu também em alemão às perguntas que the foram feitas em romanche. Diante de uma pergunta mais complicada, pediu que lhe traduzisse para o alemão, com a justificativa de que a pergunta era complexa demais. As mulheres nativas falavam em alemão, enquanto isso, com aquela que colheu as amoras e entre si e comigo em romanche. É quase desnecessário dizer que elas se conheciam bem.

Em Lumbrein, fala-se o sobresselvano. Aprende-se o alemão oficial na escola, por volta dos 10 anos, e o alemão suíço vem mais tarde, através de contatos com pessoas não nascidas ali. Bem diferente é a situação de Prez e Sarn: o alemão suíço muitas vezes é a língua de um dos pais e a criança cresce bilíngue ou apenas falante de alemão. Como a escola nessas localidades não ensina subselvano, desde os primeiros anos de escola já tem contato com alemão oficial. Ou seja, em Lumbrein a ordem cronológica na aquisição linguística para o estabelecimento do bilinguismo é: (1) romanche, (2) alemão oficial e (3) alemão suíço; em Prez/Sarn é: (1) alemão suíço+romanche, (2) alemão oficial. ${ }^{59}$ Até a década de 1950, quando um casal misto tinha filhos, o romanche se mantinha por

\footnotetext{
${ }^{59}$ Lembra-me a afirmação bastante procedente, ouvida da boca do prof. George Darms, que o romanche só passou a correr risco de extinção a partir do momento que seus falantes aprenderam a falar alemão suíço, uma vez que o alemão oficial não oferecia grande ameaça à sua sobrevivência.
} 
mais uma geração quando pelo menos a mãe falava romanche, uma vez que era ela quem cuidava dos filhos. Hoje em dia, mesmo quando a mãe fala romanche, os filhos se tornam monolíngues de alemão. Isso também ocorre quando, por exemplo, os pais usam falares romanches distintos. Nas três comunidades mencionadas, escrever em romanche parece restrito a professores, mas, quando a língua materna é romanche admitem que é mais difícil escrever (e às vezes ler) alemão do que em romanche. De qualquer forma, a distância entre a escrita tradicional romanche e o falar local faz surgir, com frequência, a afirmação de que não sabem escrever "corretamente" o romanche ou que não "sabem" escrever em romanche. Para os falantes das duas comunidades subselvanas supracitadas, o romanche é língua ágrafa e têm extrema dificuldade de entender a Deckmantelorthographie daquele falar. Além dos professores, também os párocos de Lumbrein se valem com frequência do romanche escrito. É importante a informação de que celebram suas cerimônias em sobresselvano, contudo nas localidades de Prez e Sarn, que são evangélicas, e os cultos são todos em alemão. De qualquer forma, a situação de Prez e Sarn parece muito mais comum do que a de Lumbrein e o alemão suíço tem se tornado a língua veicular, ao passo que o romanche assumiu a posição de língua familiar. Ambos, portanto, não são utilizados em situações formais. Aí surge um caso típicamente suíço: a língua falada em situações formais é o próprio alemão oficial. O alemão é o modo de se escapar de problemas de comunicação: em qualquer situação em que esse risco pode surgir, fala-se em alemão. Mas também aqui há nuances entre os dois grupos: se se dirige a um desconhecido, um romanche falará alemão (a menos que saiba que ele fale romanche). Se está diante de um conhecido, só se falará romanche se ele também for romanche. Mas, mesmo assim, se esse falante de romanche não se utiliza do mesmo falar que o interlocutor, é bem possível que a conversação continue em alemão. Baseando-se ainda nos estudos de Solèr, em Lumbrein, diante de um subselvano, há 91\% de 
chance de um habitante de Lumbrein falar em romanche, mas diante de um engadino, esse valor cai para 42\%. Já com um habitante de Prez/Sarn, diante de um sobremirano, há 30\% de chance de usar romanche, mas com um engadino, apenas $20 \%$. O alemão, portanto, é um "facilitador de comunicação" e dominá-lo se tornou, ao longo dos séculos, imprescindível. Isso é resultado de um somatório muito complexo de fatores, que envolvem fatos históricos e consciência de grupo. Para um sobresselvano, o sobremirano é mais importante do que o subselvano: além de ser um falar mais distinto, trata-se de um grupo maior, mais uniforme e de pessoas católicas como eles. Em contraposição, seus vizinhos subselvanos, protestantes, fragmentados espacial e linguisticamente e de falar muito próximo, não recebem o mesmo status. Os romanches sentem-se antes de tudo "grisões" (Bündnervolk, pievel grischun) e, desde o século XIX, "suíços": uma consciência de unidade entre eles ou uma oposição entre os falantes de alemão que convive no mesmo território praticamente não existe: afinal, eles também são falantes de alemão. Como diz Scheuermeier, citado por Solèr, ${ }^{60}$ o alemão não é uma língua estrangeira para eles, mas: "a língua dos seus concidadãos, vizinhos, colegas de trabalho, amigos do mesmo círculo, correligionários políticos, dos próprios parentes, talvez até, do pai ou da mãe, ou da avó”.

De qualquer forma, os contatos com o alemão valesiano é menor do que com a variante chamada "dos Grisões" (Bündnerdeutsch). É de se imaginar, que mesmo se esforçando para falar o alemão oficial, um suíço deixe transparecer peculiaridades do alemão suíço. Um habitante de Berna, para expressar algo como "não pode ser", escreveria sempre (como faria um alemão ou um austríaco) das kann nicht sein mas diria, em alemão suíço, algo como [tas ' $\chi$ a nøt 'si]. Quando tenta falar

${ }^{60}$ SOLÈR. Sprachgebrauch und Sprachwandel: eine theoretische Faktoranalyse und die Pragmatik der Sprachbehandlung bei den Rätoromanen von Lumbrein mit einem Vergleich der Germanisierung in Präz und Sarn, p. 26. 
alemão oficial, dificilmente dirá conforme a pronúncia padrão alemã

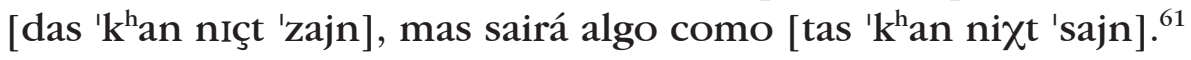
Por outro lado, as diferenças regionais dos diversos dialetos suíços tendem, cada vez mais, devido aos atuais meios de comunicação, a se neutralizar numa koiné. Formas muito marcadas acabam sendo anuladas: "o homem velho" se diria der alte Mann em alemão oficial, em Berna se diz [tər 'aut 'ma:] e em Zurique, [tr 'alt 'mo:]. Surgem espontaneamente, na boca dos falantes, formas como [tər 'alt 'ma:] ou [tər 'alt 'mo:], evitando-se assim a vocalização da consoante $/ /$, fenômeno típico de Berna. ${ }^{62}$

Se o alemão oficial pode ser falado, ainda que com "sotaque suíço" também o alemão suíço pode ser escrito e há uma relativa padronização na grafia. Escrever em alemão suíço se restringe ainda muito a situações literárias e populares. Nos dois exemplos acima, surgem grafias como das cha nöd sy "não pode ser" e der alt Maa "o homem velho". Com referência à história da raposa, a informante do dialeto de Zurique afirmou que dizer De Fuchs hät wider emaal Hunger ghaa é mais natural do que De Fuchs isch wider emaal hungrig gsy, onde se observa o bungrig "faminto" migrando do alemão oficial para o alemão suíço. $\mathrm{O}$ mesmo se pode dizer de Wänn du soo schöön singe chasch, wi d uusgseesch, que soa muito mais natural do que uma tradução literal como Wänn din Gsang soo schöön isch wi dis Uusgsee, com substantivos abstratos em vez de verbos. Também para "corvo", o dialeto diz Chrëë, mas é possível dizer Raab. Expressões como Daas

\footnotetext{
${ }^{61}$ Quando se refere ao eventual uso falado da língua oficial, que é mormente escrita, um suíço costuma usar uma curiosa contradição: gesprochene Schriftsprache ("alemão escrito falado"). Mesmo no alemão oficial escrito, há uma longa lista dos chamados "helvecismos". Do ponto de vista ortográfico, por exemplo, não se usa nunca a letra $\beta$, que se substitui sempre por $s$ s. Verbos como verunfallen "acidentar-se" só aparecem no alemão da Suíça (MEYER Duden - wie sagt man in der Schweiz? Wörterbuch der schweizerischen Besonderheits).

${ }^{62}$ No texto da raposa, numa situação mais formal, a pessoa evita falar Schnabu, auune, Vögu mas diria Schnabl, allne, Vögl.
} 
wëër dänn öppis Fäins são mais coloquiais mas menos neutras e úteis para a koiné do que algo como Daas würd mer äu no passe. O mesmo se diria para Duu bisch dänn e Schööni! muito marcado em vez do neutro Wi schöön du bisch! No dialeto de Chur, antigas formas como gsäha e uusgsiasch perdem terreno para formas mais próximas da koiné, a saber, gsee, uusgseesch.

A situação, mais próxima da realidade, poderia ser expressa pelo seguinte esquema:

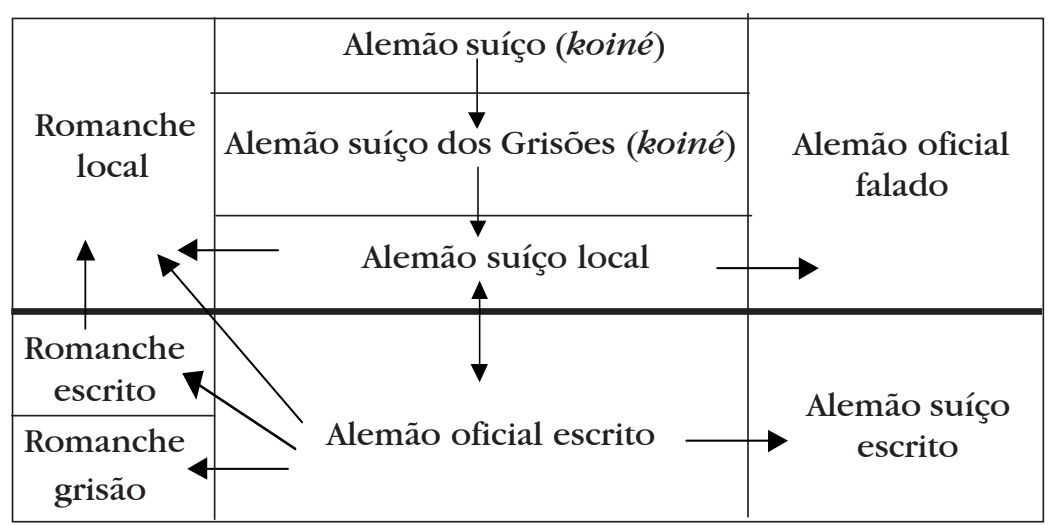

As setas acima indicam as influências. Elas não ocorrem em todas as direções, mas há direções específicas: o alemão suíço local pode interferir na realização do alemão oficial escrito (como um substrato), mas o contrário também pode ocorrer (comoforma erudita). ${ }^{63}$ Dificilmente uma palavra do romanche entrará num

63 Também o romanche escrito pode interferir com cultismos na língua falada local. Solèr aponta uma série de palavras, torneios sintáticos e variação lexical que apontam para uma fala "mais cuidadosa" (de inspiração na fala litúrgica) em contraposição a uma fala "mais informal". Assim, na pronúncia litúrgica e no rádio, muitas vezes, o /r/ dos infinitivos é pronunciado, mas na fala normal não. Também formas mais próximas da escrita são associadas à pronúncia mais cuidadosa: pli "mais", tgietschen "vermelho", nua "onde", otg "oito", mondi "ande", piarsas "perdidas", vegnir "vir", fuva "era" são formas restritas a situações mais formais, uma vez que no dia-a-dia se usam $p i$, tschietschen, ne, o, moni, persas, gni, era. Também a forma megler "melhor" é mais formal que pi bain. Verbos comogartegiar 
texto alemão, por causa do prestígio maior da língua escrita alemã sobre a língua escrita romanche, mas o contrário ocorre com frequência. Observando o sentido das setas, pode-se afirmar que os campos para onde elas se direcionam são formas restritas a situações especiais (ou muito familiares ou muito formais). Para o dia a dia sobram somente o alemão suíço local, influenciado pela koiné e o alemão oficial escrito. É nesse sentido que caminham as áreas dos Grisões em que há sério risco de extinção do falar romanche local. O quadro por si só, sem as setas, nos poderia fazer pensar em línguas "puras" ou em sistemas estruturalmente excludentes, mas a situação real é bem outra, como se pode depreender. Mesmo no esquema acima, tão complexo, a situação conversacional se mostra ainda mais fluida. De fato, as setas indicam que o alemão invade a área romanche, tanto na fala quanto na escrita. O fenômenos conhecido como code switching é muito frequente. ${ }^{64}$ Solèr ${ }^{65}$ cita o seguinte exemplo: Sche vom a Cuira, ei, wi say ma Stieramarcht, fiara da tors... "se vou a Cuira (em sobresselvano)... hmm... como dizer, feira de touros (em alemão suíço)... feira de touros (em sobresselvano)." A simples evocação

"conseguir", vegnir "vir" e palavras como aber "mas", schon "já" são mais informais que reussir, arrivar, par encunter, gia. Também na conjugação, para expressar "eles tenham" associam-se formas como hagien, hagitgen, hagien, hagen, hatgen como "mais formais" (embora só hagien seja oficial) do que baiten, hagn (SOLÈR. Sprachgebrauch und Sprachwandel: eine theoretische Faktoranalyse und die Pragmatik der Sprachbehandlung bei den Rätoromanen von Lumbrein mit einem Vergleich der Germanisierung in Präz und Sarn, p. 143-150).

${ }^{64}$ Nos textos antigos encontram-se vários exemplos, comofar bekandt (DECURTINS. Rätoromanische Chrestomatie, v. 1, p. 422, 28) "apresentar" ou nos traurigs umstands (DECURTINS. Rätoromanische Chrestomatie, v. 1, p. 422, 28) "nossas tristes situações". Nesses casos de empréstimos lexicais, as desinências gramaticais, como o plural em -s, são claramente românicas.

${ }^{65}$ SOLÈR. Sprachgebrauch und Sprachwandel: eine theoretische Faktoranalyse und die Pragmatik der Sprachbehandlung bei den Rätoromanen von Lumbrein mit einem Vergleich der Germanisierung in Präz und Sarn, p. 72. 
de Cuira, onde a língua corrente é o alemão, fez o falante invocar não só a palavra Stieramarcht ("praça de touros", em oficial, Stiermarkt), mas também a frase wi say ma "como dizer" (em oficial, wie sagt man). Em seguida, volta ao sobresselvano, por lembrar que o interlocutor é também romanche conhecido seu.

Isso ocorre em maior frequência em outras regiões: nem sempre se encontrará, por exemplo, um falante de puter, filho de pai e mãe também falantes de puter, casado com um(a) outro(a) falante de puter: o que ocorre é que falantes de puter têm pai ou mãe ou ainda cônjuge falantes de alemão, (ou italiano ou valáder etc.). Nesses casos, o uso do puter se restringirá ao nível passivo. Quando esse falante se arrisca a falar puter, misturará frases inteiras em alemão, na tentativa de se fazer entender. Quer falar puter, mas sabe que o interlocutor entende alemão, língua da qual se vale para que a conversa flua. Isso não acontece só quando o falante não sabe ou momentaneamente não se lembra de uma palavra em puter, mas sabe como dizê-la em alemão. A mistura parece ocorrer, quer ele conheça, quer não as palavras, conforme as flutuações de humor do falante. Às vezes, até julga que esteve falando apenas puter, quando, na realidade, inseriu trechos inteiros em alemão.

\section{Conclusões}

$\mathrm{Na}$ instância do discurso, o falante bilíngue muitas vezes cruza fenômenos de sistemas linguísticos diferentes. Uma palavra do alemão inesperadamente surge na fala de uma pessoa que está se expressando em romanche. O uso eventual de uma palavra, como visto, motivado por um lapso de memória ou simplesmente por saber que o interlocutor entende alemão, é muito diferente do uso constante de outra palavra, que pode caracterizar o idioleto do mesmo falante ou da fala de determinado grupo social. Nesse caso, o uso é motivado pela inexistência ou desconhecimento da palavra romanche. Isso ainda pode ocorrer quando o falante ainda 
tem certa consciência de que está "enxertando" uma palavra de um sistema noutro. Mas há ainda ocasiões em que algumas palavras adquirem significados inexistentes na língua original. Nesse caso, em que pode haver ou não manutenção do significante, o falante não tem a mesma consciência. ${ }^{66}$ Não há outra motivação senão comunicar-se. As causas de seu uso são desconhecidas para o falante, de modo que ele só percebe a coincidência de formas quando chamam sua atenção. Num último estágio, a inconsciência é total, de modo que nem mesmo a origem é conhecida. Ficam então estabelecidos quatro níveis teóricos de cruzamentos linguísticos no discurso: cruzamento eventual; cruzamento consciente; cruzamento inconsciente; cruzamento cristalizado. Cumpre observar que esses cruzamentos existem sempre, independentemente do grau de parentesco entre as duas línguas envolvidas, ou seja, tanto para os chamados "estrangeirismos", entre os quais interessam para este trabalho os "germanismos" (romanche/ alemão), quanto para falares distintos do romanche (sobresselvano/subselvano) ou para o mesmo falar (sobresselvano na fala mais cuidadosa / sobresselvano na fala mais informal). Os cruzamentos também podem ocorrer no nível do significante e/ou no do significado. Quando atinge precipuamente o nível do significante chama-se empréstimo, já quando ocorre apenas no nível do significado trata-se de um decalque. Nesses cruzamentos, criam-se, às vezes, oposições antes inexistentes ou anulam-se antigas oposições, resumindo, há consequências no eixo paradigmático. Também podem criar torneios expressivos ou estruturas sintáticas antes inexistentes, assimcomo deixar de utilizar antigos torneios expressivos ou estruturas sintáticas; dito, doutro modo, ocorrem consequências no eixo sintagmático.

\footnotetext{
${ }^{66}$ Os falantes de romanche usam muitas Abtönungspartikel do alemão, que, muitas vezes, exprimem nuances difíceis de serem traduzidas nas línguas românicas: aber, schon, balt, also, grad, eben, sowieso, fertig, überbaupt, doch, zwar, entre outras.
} 
Resumen: Los manuales de linguística o filología románica costumbran incluir el reto-románico como una de las principales lenguas neolatinas, al lado del portugués, español, francés, italiano y rumano. Pero tal denominación se refere en la realidad a un conjunto extremamente heterogéneo de lenguas, con una profunda fragmentación dialectal. Se añade a eso el reciente problema de la estandarización de la norma escrita. Este artículo pretende especificamente presentar la situación linguística actual de los Grisones y el problema de la convivencia del romanche con los dialectos alemanes e italianos.

Palabras-llave: Reto-románico; dialectología; contacto linguístico.

\section{Referências}

ANDERLAN-OBLETTER, A. La rujeneda dla oma: gramatica dl ladin de Gherdëina. Urtijëi: Istitut Pedagogich Ladin/Lia Maestri de Gherdëina, 1991.

ASCOLI, G. I. Saggi Ladini. Archivo Glottologico Italiano, v. 1, p. 316-353, 1873.

BATTISTI, C. Sulla pretesa unità ladina. Archivo Glottologico Italiano, v. 22-23, p. 409-444, 1929.

BEC, P. Manuel pratique de philologie. Paris: A. \& J. Picard, 1971. v. 2.

BERNARDI, R. et al. Curs de gherdëina. Zürich/Innsbruck/Urtijëi. Istitut Ladin "Micurá di Rü", 1999.

BEZZOLA, R. R.; TÖNJACHEN, R. O. Dicziunari tudais-ch-ladin. Chur: Lia Rumantscha, 1997.

CAVIEZEL, E. Geschichte von Verschriftung, Normierung udn Standardisierung des Surselvischen. Bern: Wittwer-Service, 1993.

COLLE, L. et al. Vocabolario italiano-ampezzano. Bolzano: Cassa Rurale et artigiana di Cortina d'Ampezzo e delle Dolomiti, 1997.

CROATTO, E. Vocabolario ampezzano. Cortina d'Ampezzo: Cassa Rurale ed Artigiana, 1986. 
DA COL, G. L'idioma ladino a Cibiana di Cadore. Pieve d'Alpago: Nuove Edizioni Dolomiti, 1991.

DARMS, G.; GROSS, M.; DAZZI, A.-A. Wörterbuch rätoromanischdeutsch deutsch-rätoromanisch. Zürich: Langenscheidt, 1989.

DARMS, G.; GROSS, M.; DAZZI, A.-A. Pledari grond tudestg-rumantsch rumantsch-tudestg. Mustér: Lia Rumantscha, 1993.

DECURTINS, A. Zur Morphologie der unregelmässigen Verben im Bündnerromanischen: historisch-deskriptive Studie mit besonderer Berücksichtigung der Sur- und Sutsetsischen. Bern: A. Francke, 1958.

DECURTINS, A. Vom Vulgärlatein zum Rätoromanischen. Chur: Historisch-antiquarische Gesellschaft von Graubünden, 1986.

DECURTINS, A. Rätoromanisch: Aufsätze zur Sprach-, Kulturgeschichte und zur Kulturpolitik. Chur: Società Retorumantscha, 1993.

DECURTINS, C. Rätoromanische Chrestomatie. Chur: Oktopus/Società Retorumantscha, 1983-1986. $15 \mathrm{v}$.

DICZIUNARI RUMANTSCH GRISCHUN. Chur: Institut dal DRG, 19391997.

DIEKMAN, E. Probleme und Aspekte von Kodifizierungsbemühungen des Bündnerromanischen und Bericht über eine Umfrage zur Rezeption und Akzeptanz des Rumantsch Grischun als gesamtbündnerromanischer Schriftsprache. In: DAHMEN, Wolfgang et al. Zum Stand der Kodifizierung romanischer Kleinsprache. Tübingen: Gunter Narr, 1991. p. 69-104.

FAGGIN, G. Gramatica friulana. Campoformido: Ribis, 1997.

GANZONI, G. P. Grammatica ladina: grammatica sistematica dal rumauntsch d'Engiadin'Ota per scolars e creschieus da lingua rumauntscha e tudas-cha. Samedan: Lia Rumantscha/Uniun dals Grischs, 1983.

GARTNER, T. Rätoromanische Grammatik. Heilbronn: Gebr. Henningen, 1883.

GROSS, M. et al. Rätoromanisch: facts and figures. Chur: Lia Rumantscha, 1996.

HAIMAN, J.; BENINCÀ, P. The Rhaeto-Romance languages. London/New York: Routledge, 1992.

HOLTUS, G et al. Lexikon der Romanistischen Linguistik. Tübingen: Max Niemeyer, 1989. v.3. 
ILIESCU, M. Zur Normierung der Graphie des Friaulischen. In: DAHMEN, W. et al. Zum Stand der Kodifizierung romanischer Kleinsprache. Tübingen: Gunter Narr, 1991. p. 41-53.

JABERG, K. Considérations sur quelquers caractères généraux du romanche. In:__ Mélanges de linguistique offerts a Charles Bailly. Genève: George \& Cie, 1939. p. 283-292. p. 283-292.

JENNY, L. Wier und schii: dialektgschichtä va Tschappina. Chur: Walservereinigung Graubünden/Terra Grischuna, 1985.

KREFELD, T. Der surselvische Wortschatz, die questione ladina und die quantitative Arealtypologie. In: Ladinia, sföi culturâl dai ladins dles Dolomites. San Martin de Tor, 18: 261-288, 1994.

LEONARD, C. Proto-Raeto-Romance and French. Language, v. 40, p. 32-32, 1962.

LEONARD, C. The vocalism of Proto-Raeto-Romance. Orbis, v. 21, p. 61-100, 1972.

LIVER, R. Manuel pratique de romanche sursilvan-vallader: précis de grammaire suivi d'un choix de textes. Chur: Lia Rumantscha, 1991.

MANI, C. Pledari sutsilvan rumàntsch-tudestg tudestg-rumàntsch. Chur: Lia Rumantscha, 1977.

MENZLI, G. Curs da rumantsch grischun. Chur: Lia Rumantscha, 1995. MEYER, K. Duden - wie sagt man in der Schweiz? Wörterbuch der schweizerischen Besonderheits. Mannheim/Leipzig/Wien/Zürich: Duden, 1989.

NAZZI, G.; NAZZI, L. Dizionario italiano-friulano friulano-italiano. S/: Antonio Vallardi, 1997.

NAZZI, G. et al. Dictionnaire frioulan; français-frioulan-frioulanfrançais. Acuilee: Ribis, 1995.

PEER, O. Dicziunari rumantsch ladin-tudais-ch. Chur: Lia Rumantscha, 1962.

PELLEGRINI, G. B. Saggi sul ladino dolomitico e sul friulano. Bari: Adriatica, 1972.

PELLEGRINI, A. Vocabolario fodom-taliân-todâsè Wörterbuch. Bolzano: Ferrari-Auer, [s. d.].

ROSSI, H. von. Ladinisches Wörterbuch-vocabolario ladino (brach) -tedesco. Innsburck/ Vich, Universität Innsburck/ Istitut Cultural Ladin, 1999. 
RITTER, A. Historische Lautlebre der ausgestorbenen romanischen Mundart von Samnaun. Gerbrünn bei Würzburg: A. Lehmann, 1981.

SALVIONI, C. Ladinia e Italia. Rendiconti del R. Istituto Lombardo di Scienze e Lettere. Pavia, 1917. p. 41-78.

SCHMID, H. Richtlinien für die Gestaltung einer gesamtbündnerromanischen Schriftsprache Rumantsch Grischun. In: ANNALAS DE LA SOCIETAD RETORUMANTSCHA. Puntraschigna, Grafiscrit, v. 102, p. 3-36, 1989.

SCHMID, H. Wegleitung für den Aufbau einer gemeinsamen Schriftsprache der Dolomitenladiner. San Martin de Tor/Vich, Istitut Cultural Ladin "Micurá de Rú"/Istitut Cultural Ladin "Majon de Fascegn”, 1998.

SOLÈR, C. Sprachgebrauch und Sprachwandel: eine theoretische Faktoranalyse und die Pragmatik der Sprachbehandlung bei den Rätoromanen von Lumbrein mit einem Vergleich der Germanisierung in Präz und Sarn. Zürich: Zentralstelle der Studentenschaft, 1983.

SONDER, A; GRISCH, M. Vocabulari da Surmeir rumantsch-tudestg tudestg-rumantsch. Chur: Lia Rumantscha, 1970.

SPESCHA, A. Grammatica sursilvana. Chur: Casa Editura per Mieds d'instrucziun, 1989.

TAJINA, A. D. Dizionèr talian-fascian-talian. Trento: Artigianelli, 1998.

THÖNI, G. P. Rumantsch-Surmeir: grammatica per igl idiom surmiran. Chur: Lia Rumantscha, 1969.

VIELI, R.; DECURTINS, A. Vocabulari romontsch tudestg-sursilvan. Chur: Lia Rumantscha, 1975.

VIELI, R.; DECURTINS, A. Vocabulari romontsch sursilvan-tudestg. Chur: Lia Rumantscha, 1995.

WEINREICH, U. Languages in contact. Paris: Mouton, 1970.

Recebido para publicação em janeiro de 2009.

Aprovado em março de 2009. 